\title{
Changes in Operational Efficiency and Firm Performance: A Frontier Analysis Approach*
}

\author{
BOK BAIK, Seoul National University \\ JOON CHAE, Seoul National University \\ SUNHWA CHOI, Lancaster University \\ DAVID B. FARBER, McGill University
}

\section{Introduction}

In this study, we examine the relation between operational efficiency ${ }^{1}$ and firm performance. In particular, we are interested in examining whether measures of operational efficiency derived from frontier analysis improve profitability forecasts and, if so, whether capital market participants impound the predictive information in the efficiency measures. ${ }^{2}$ This is important to understand because future profitability is linked to firm valuation (Ohlson 1995). A stream of prior research has used simple financial statement ratios (e.g., asset turnover) as proxies for efficiency to examine the relation between efficiency and performance; these studies show that changes in asset turnover improve forecasts of changes in future profitability (e.g., Fairfield and Yohn 2001; Soliman 2008). Another set of studies uses frontier analysis to examine the link between efficiency and performance (e.g., Alam and Sickles 1998; Greene and Segal 2004), but none of these studies has linked frontierbased efficiency measures with future profitability. ${ }^{3}$ We seek to fill this gap by conducting a broad examination of whether efficiency changes based on frontier analysis are incrementally informative to simple financial ratios about profitability changes and, if so, whether equity investors and analysts impound this incremental information.

Frontier analysis generates an optimized efficiency measure that is essentially a "best practice" frontier against which to evaluate the performance of individual decision making

* Accepted by Dan Segal. We thank two anonymous reviewers, Tae-Sik Ahn, Rajiv Banker, Larry Brown, Jong-Hag Choi, Lynn Hannan, Chris Ittner, Marilyn Johnson, Steve Orpurt, Arianna Pinello, Willie Reddic (discussant), Dan Segal (editor), Robin Sickles, Ramgopal Venkataraman (discussant), Teri Yohn, Yong Zhang, and participants at the SNU-SMU-HKUST research camp, the 2011 AAA annual meeting, the 2011 FARS mid-year meeting, Georgia State University, and McGill University for their helpful comments and suggestions. Bok Baik and Joon Chae acknowledge financial support from the Institute of Management Research, Seoul National University.

1. We interchangeably refer to operational efficiency and efficiency, unless otherwise noted.

2. Prior research supports the validity of measures based on frontier analysis as proxies for operational efficiency. For example, Thore, Kozmetsky, and Phillips (1994) estimate frontier analysis scores for the computer industry and find that companies classified as inefficient experienced a static or declining market share, while efficient companies displayed rapid sales growth, increasing market share, and increasing market capitalization. Anecdotes also suggest that frontier analysis has been introduced to measure operational efficiency in industries (see, e.g., Norton 1994; Maney 2003).

3. Additionally, research using frontier analysis has mainly focused on samples of firms in a particular industry, thereby limiting the generalizability of results across industries. A notable exception is Demerjian, Lev, and McVay 2012, who use a large sample across multiple industries and find a positive relation between efficiency and current and past returns. Our study differs from Demerjian et al. 2012 in several important ways, particularly with respect to research design issues. We more fully explain these differences in section 2. 
units (DMUs). A natural question that arises is that, given its computational complexity, what advantage does frontier analysis have over simple financial ratios that proxy for operational efficiency (e.g., asset turnover)? Although frontier-based measures are harder to calculate and understand than simple financial ratios, a significant advantage that frontier analysis has over simple financial ratios is that it implicitly allows for differential weighting among inputs, which should yield a more precise measure compared to simple financial ratios. By contrast, simple financial ratios are easier to calculate and understand than measures derived from frontier analysis, but they are likely to be less precise than measures derived from frontier analysis. Even if a financial statement user constructed a non-frontier-based measure using multiple inputs and outputs, an exogenous weighting scheme would need to be applied. Such a weighting scheme would likely result in the loss of information about operating decisions that firms make. ${ }^{4}$ Additionally, stochastic frontier analysis distinguishes between random shocks (i.e., pure noise) and technical inefficiencies in the production function, while simple financial ratios cannot do so. In sum, we argue that frontier analysis likely provides a more comprehensive and conceptually appealing measure of a firm's operational efficiency than simple financial ratios. If our argument holds, then the information in measures of efficiency based on frontier analysis should be incremental to the information in measures of efficiency based on simple financial ratios, leading to improved profitability forecasts.

We employ measures of operational efficiency derived from Data Envelopment Analysis (DEA) and Stochastic Frontier Analysis (SFA), two commonly used techniques of frontier analysis. Additionally, because we are interested in understanding how changes in efficiency impact future performance, we employ the Malmquist 1953 technique to derive our empirical measures of changes in efficiency. ${ }^{5}$ For brevity of exposition, we more fully describe these measures in Appendices 1 and 2.

We execute our tests of the relation between changes in efficiency and changes in performance using a large sample over the years 1976-2008. Results indicate that efficiency changes based on both DEA and SFA are positively associated with changes in current and future profitability, even after controlling for fundamental signals (e.g., Abarbanell and Bushee 1997) and changes in asset turnover (e.g., Fairfield and Yohn 2001). We also show that the predictive power of our efficiency measures is economically incremental to that of simple financial ratios. These findings imply that innovations in frontier analysisbased efficiency measures provide information that improves profitability forecasts.

We next assess whether equity investors impound the predictive information in our efficiency measures. We find that efficiency changes are positively associated with current and future returns, implying that although investors recognize the informational value of efficiency changes, investors do not fully reflect this information in firms' market value. Importantly, results hold after controlling for fundamental signals and changes in asset turnover.

We also examine whether analysts impound the predictive information in our efficiency measures. We find that, while changes in both of our efficiency measures are positively associated with analysts' forecast revisions, our efficiency measures are not associated with analysts' forecast errors. Taken together, these results suggest that analysts fully impound innovations in efficiency. Our results are robust to a battery of sensitivity analyses, including estimating the DEA measure using additional input variables, control-

4. We thank an anonymous referee for highlighting this issue.

5. Although the Malmquist index has been used as a productivity measure (Färe, Grosskopf, Lindgren, and Roos 1992), our characterization of the Malmquist index as a measure of efficiency follows prior research that employs the Malmquist index (see, e.g., Cummins, Tennyson, and Weiss 1999; Chang, Choy, Cooper, and Ruefli 2009). 
ling for market-adapted earnings, and replacing accounting fundamentals with accruals from Richardson, Sloan, Soliman, and Tuna 2005.

Our study contributes to the literature on the performance consequences associated with innovations in efficiency by showing that, for a large sample across multiple industries, changes in efficiency measures derived from frontier analysis enhance profitability forecasts, and that users of these forecasts impound this information, although equity investors do not completely do so. To the best of our knowledge, our study is the first to show that changes in efficiency measures from frontier analysis are useful for predicting future profitability. We also provide evidence that frontier-based efficiency changes are incremental to efficiency changes based on simple financial ratios in explaining firm performance. We thus extend prior research that has used simple financial ratios as proxies for efficiency (e.g., Fairfield and Yohn 2001; Nissim and Penman 2001; Soliman 2008), as well as research that has used frontier analysis to generate efficiency proxies (e.g., Alam and Sickles 1998: Greene and Segal 2004; Demerjian et al. 2012). Our study should be of interest to researchers because we provide a better understanding of the relation between operational efficiency and performance. It should also be of interest to analysts and investors who may rely on our approach when making investment decisions.

The rest of this paper is organized as follows. In section 2, we review the relevant literature and develop hypotheses. In section 3, we provide the research design and data. We report the results of our empirical tests in section 4. Section 5 presents robustness tests and section 6 provides the summary and conclusions.

\section{Related literature and hypotheses}

The accounting literature has used both simple accounting ratios and frontier analysis to generate proxies for operational efficiency to examine the relation between operational efficiency and firm performance. We next discuss this literature and develop our hypotheses.

\section{Operational efficiency based on simple accounting ratios}

There is a rich literature devoted to understanding the relation between accounting information and firm performance, including stock returns and future earnings. For example, $\mathrm{Ou}$ and Penman (1989) construct the Pr-measure using an array of financial statement ratios and find that it predicts the sign of one-year-ahead earnings changes. Lev and Thiagarajan (1993) identify a set of 12 fundamental accounting signals used in Value Line analyst reports, such as receivables growth and inventory growth, and examine the predictive power of these signals for current returns. Abarbanell and Bushee (1997) extend Lev and Thiagarajan 1993 and document that fundamental signals have predictive power for future earnings changes and that analysts' forecast revisions fail to fully impound the information in fundamental signals.

A more recent set of studies uses a valuation framework to guide the analyses. Fairfield and Yohn (2001) decompose changes in return on net operating assets into changes in profit margin and changes in asset turnover and find that only changes in asset turnover are useful for predicting future profitability changes. They argue that changes in asset turnover are more persistent than changes in profit margin, thereby leading to higher firm value. This argument corresponds with Penman's text on financial statement analysis (2007: 382), in which he indicates that firms can lever up margins by using operating assets more efficiently to generate sales. Nissim and Penman (2001) and Penman and Zhang (2003) also show that changes in asset turnover are related to current and future earnings changes. Soliman (2008) extends these prior studies by examining whether equity investors and analysts impound the predictive information in changes in asset turnover. $\mathrm{He}$ finds 
evidence suggesting that investors and analysts do not fully impound information in changes in asset turnover.

\section{Operational efficiency based on frontier analysis}

The prior literature using frontier analysis to examine the association between efficiency and performance employs both DEA and SFA. DEA has been widely used in operations research and management accounting research to evaluate organizations' efficiency (see Callen 1991 for a review). For example, studies have used DEA to measure relative efficiency for cost variance analysis and performance measurement, mostly for nonprofit organizations (Callen and Falk 1993; Mensah and Li 1993; Rouse, Putterill, and Ryan 2002). Alam and Sickles (1998) relate DEA efficiency innovations to stock performance using a panel of 11 airline companies and find that DEA efficiency innovation in a quarter is associated with stock market performance in the following two months.

SFA is another method widely used to measure efficiency (e.g., Battese and Coelli 1992, 1995; Dopuch and Gupta 1997; Dopuch, Gupta, Simunic, and Stein 2003; Greene and Segal 2004; Callen, Morel, and Fader 2005). Using data reported by public school districts, Dopuch and Gupta (1997) employ SFA to estimate benchmark performance standards in relative performance evaluation. Using both SFA and DEA, Dopuch et al. (2003) estimate the relative efficiency of audit production and find that inefficiencies in audit production are associated with reduced audit fees, consistent with the cost of inefficiency being partially borne by the accounting firm. Callen et al. (2005) use SFA to measure plant-level efficiency for firms that have adopted just-in-time (JIT) production.

Several studies have examined the performance implications of efficiency measures and/or efficiency changes using frontier analysis. Greene and Segal (2004: 230) argue that "cost inefficiency affects profits and growth through the negative effect of wasted resources on earnings and cash flows." This implies that more operationally efficient firms should be more profitable. Greene and Segal (2004) use SFA and document a contemporaneous association between profitability (ROE and ROA) and efficiency in the U.S. life insurance industry. Cummins and Xie (2008) use DEA and show a positive relation between firm efficiency and stock market reactions to acquisitions and divestitures in the U.S. propertyliability insurance industry.

In a study closely related to ours, Demerjian et al. (2012) use a large sample of firms across industries and demonstrate that managerial ability scores derived from DEA are positively associated with manager fixed effects. However, there are important differences between Demerjian et al. 2012 and our study. One important difference between our studies is that we perform a comprehensive examination of the relation between operational efficiency and firm performance that includes examining whether investors and analysts impound the predictive information in efficiency changes. In contrast, Demerjian et al. (2012) test whether their efficiency scores reflect managerial ability. Another important difference is that we use both DEA and SFA, while Demerjian et al. (2012) focus on DEA. Thus, we show that our results are not sensitive to a particular methodology, thereby enhancing confidence in our results. Our studies also differ in that we use a firm-level measure of efficiency, while Demerjian et al. (2012) use a manager-level measure of efficiency. This is important because we are interested in how a firm's efficiency is related to performance, while Demerjian et al. (2012) are interested in how a CEO's ability relates to firm performance.

\section{Hypotheses}

In sum, the literature using simple accounting ratios as measures of operational efficiency highlights that changes in asset turnover, rather than its level, predict changes in current 
and future profitability. The rationale for these findings is that levels of asset turnover reflect industry membership or operating structure (Ge and Soliman 2007), while changes in asset turnover indicate that a firm's ability to generate revenues from operating assets has changed, implying that future efficiency will change. As we argued earlier in the paper, efficiency measures based on frontier analysis are likely to be more comprehensive and conceptually appealing than simple financial ratios such as asset turnover. If so, then we expect frontier-based measures to provide incremental predictive power about future profitability changes compared to simple ratios. While the frontier analysis literature shows that efficiency is related to firm performance, missing from this literature is an examination of the relation between efficiency changes and future profitability changes. We seek to fill this void with our study.

Because profitability is determined by how efficiently firms utilize available resources to maximize outputs, there should be a link between efficiency and profitability. We expect that firms which efficiently convert inputs to outputs will outperform firms that are not as efficient. To the extent that an increase in operational efficiency improves profitability, we expect to observe a positive relation between changes in frontier-based measures of efficiency and current profitability changes. Moreover, we expect efficiency changes in the current period to predict changes in future profitability if efficiency changes in the current period persist. Our argument for why efficiency changes could persist is as follows. Efficiency changes indicate that a firm's ability to generate sales from investments in capital and production processes has changed. Competitors are less likely to capture sales from firms with efficient production processes because of the enormous costs involved in overhauling factories and operations, thereby protecting efficiency changes. Supporting our argument, Romer (1986) indicates that returns derived from capital are likely to persist because of frictions in the movement of capital in the economy. Moreover, as we discuss above, studies have shown that current changes in firms' efficiency are predictive of future changes in profitability (Fairfield and Yohn 2001; Soliman 2008). The preceding discussion leads to the following hypotheses, stated in the alternative form.

Hypothesis 1A. There is a positive relation between changes in operational efficiency and changes in current profitability.

Hypothesis 1B. There is a positive relation between changes in operational efficiency and changes in future profitability.

We are also interested in examining whether equity investors impound the predictive information in operational efficiency changes. To the extent that changes in operational efficiency affect changes in current and future profitability, we expect that the change in operational efficiency will be value relevant to equity investors. Thus, we predict that current returns will reflect the predictive information in operational efficiency changes. This discussion leads to our next hypothesis, stated in the alternative form.

Hypothesis 2A. There is a positive relation between changes in operational efficiency and current returns.

In an efficient market, any systematic relation should be impounded quickly in stock prices, thereby resulting in no relation between current changes in operational efficiency and future stock returns. Alternatively, if equity investors do not fully incorporate the information in efficiency changes, then there will be a positive relation between changes in operational efficiency and future stock returns (e.g., Soliman 2008). Thus, the relation between changes in operational efficiency and future stock returns is an empirical question. This argument leads to our next hypothesis, stated in the null form. 
Hypothesis 2B. There is no relation between changes in operational efficiency and future returns.

Our last set of hypotheses is concerned with whether analysts' forecasts reflect the predictive information in operational efficiency changes. Prior literature finds mixed results for this issue. One set of studies finds that analysts do not fully impound accounting information in their forecasts (e.g., Abarbanell and Bernard 1992; Bradshaw, Richardson, and Sloan 2001; Weber 2009). Directly related to our study, Soliman (2008) finds that changes in asset turnover have predictive power for future forecast errors, implying that analysts do not fully impound the information in changes in asset turnover.

By contrast, another set of studies finds that analysts efficiently process accounting information (e.g., Brown, Richardson, and Schwager 1987; Rajgopal, Shevlin, and Venkatachalam 2003; Abarbanell and Lehavy 2003; Banker and Chen 2006; Frankel, Kothari, and Weber 2006; Weiss 2010). Byard and Cebenoyan (2007) is the only study of which we are aware that has used frontier analysis to examine the relation between operational efficiency and analyst forecast properties. Specifically, using SFA as their measure of operational efficiency, Byard and Cebenoyan (2007) find that compared to simple accounting ratios such as return on assets and return on equity, SFA is more negatively associated with the absolute value of analyst forecast errors. However, Byard and Cebenoyan (2007) use a small sample over a five-year period and do not control for accounting fundamentals (Abarbanell and Bushee 1997) or asset turnover, a measure of efficiency found to be related to profitability (e.g., Fairfield and Yohn 2001).

Based on the preceding discussion, whether analysts fully incorporate information about operational efficiency in their forecasts is an empirical question. Following prior research (e.g., Soliman 2008), we focus on analyst forecast revisions and forecast errors. We formalize the preceding discussion in the following hypotheses, stated in the null form.

Hypothesis 3A. Changes in operational efficiency do not affect analysts'forecast revisions.

HyPOTHEsis 3B. Changes in operational efficiency do not affect analysts' forecast errors.

\section{Research design and data}

\section{Research design}

To measure efficiency changes, we employ two efficiency indexes from frontier analysis: (a) DEA-based Malmquist index $\left(M A L M_{-} D E A_{t}\right)$, following Färe et al. 1992 and Färe, Grosskopf, Norris, and Shang 1994 and (b) SFA-based Malmquist index (MALM_SFAt), following Coelli, Rao, O'Donnell, and Battese 2005. Because efficiency measures are derived based on the relation between inputs and outputs, it is critical to choose inputs and outputs that adequately describe a firm's production function. ${ }^{6}$

6. While there are many inputs and outputs related to firms' production functions, we choose a small set of input and output variables for parsimony. We find support for our approach in Thanassoulis, Dyson, and Foster 1987, who argue that ". . . the larger the number of inputs and outputs in relation to the number of units being assessed, the less discriminatory the method appears to be." Thus, the number of inputs and outputs included in a DEA measure should be as small as possible, subject to their reflecting adequately the function performed by the units being assessed. In a similar vein, Spottiswoode (2000) recommends a small set of input and output variables. 
Following prior research (Verma 1993; Thore et al. 1994; Demerjian et al. 2012), we use sales revenue as our sole output variable because it is a primary source of earnings and cash flows generated from firms' operating activities. Even with several intermediate outputs, sales revenue is usually the ultimate goal of these intermediate outputs. ${ }^{7}$ We use three input variables: (i) net property, plant and equipment $(P P \& E)$, (ii) cost of goods sold (COGS), and (iii) selling, general, and administrative costs $(S G \& A){ }^{8}$ Net PP\&E, measured at the beginning of the current fiscal year, represents a firm's primary capital that is utilized to generate revenue (Demerjian et al. 2012). The other two variables represent operating expenses incurred during core business activities, measured over the current fiscal year (Thore et al. 1994; Demerjian et al. 2012). We argue that our three input variables are key determinants of sales revenue and thus adequately reflect the production function in a parsimonious way. We present detailed definitions of the input and output variables in Appendix 3. ${ }^{9}, 10$

The estimation procedures for MALM_DEA $A_{t}$ and $M A L M_{-} S F A_{t}$ are distinct because they are estimated using a nonparametric and parametric method, respectively. A significant benefit of using a nonparametric method such as $M A L M_{-} D E A_{t}$ is that we do not need to impose a functional form or assign a priori factor weightings. On the other hand, using a parametric method such as $M A L M_{-} S F A_{t}$ allows us to isolate random shocks in the production process from changes in technical efficiency. To create $M A L M_{-} D E A_{t}$, we estimate the Malmquist index by industry and across two-year periods (see Appendix 1 for details). Note that for each year, we create a balanced panel for two consecutive periods (i.e., years $t$ and $t-1$ ) because the estimation of the DEA-based Malmquist index for year $t$ requires data for year $t$ and year $t-1 .{ }^{11}$ We then partition our sample into FamaFrench industries and estimate $M A L M_{-} D E A_{t}$ in each industry. The linear programming problem is solved for each firm in the estimation group with the same industry and year.

For the SFA-based measure of operational efficiency, we construct MALM_SFA by estimating the model discussed in Appendix 2 by each Fama-French industry. Note that the model for estimating $M A L M_{-} S F A_{t}$ explicitly controls for time effects by including the year variable, $T$, and therefore does not require rolling balanced panel data for two years. To estimate $M A L M_{-} S F A_{t}$, we use a half-normal distribution assumption for non-negative random variables $\left(u_{i t}\right)$. Also note that estimating $M A L M_{-} D E A_{t}$ and $M A L M_{-} S F A_{t}$ within

7. There is considerable disagreement in the literature over appropriate outputs. One perspective argues that because sales revenue is the ultimate goal of several intermediate outputs, it should be used as the sole output (see, e.g., Chandra, Cooper, Li, and Rahman 1998; Keh and Chu 2003; Leverty and Qian 2010; Demerjian et al. 2012). Moreover, Dybvig and Warachka (2010) argue for a measure of operating efficiency based on revenue so that scale decisions and costs are properly assessed. Another perspective argues that incentive mechanisms aimed at promoting productive efficiency may influence the choice of the number of outputs to produce, especially for public and regulated private entities (Stone 2002: 424). Thus, the suboptimal choice of amounts to produce may not be captured in DEA and SFA models when revenues are used as the output variable. This caveat notwithstanding, we selected sales revenue as our sole output in order to agree with the large body of empirical research that has done so.

8. Our variables are similar to those in Demerjian et al. 2012. As discussed later in the paper, we provide a sensitivity test using seven input variables for our efficiency measures, leaving the tenor of results unchanged. See section 5 for the related discussion.

9. Because we restrict our input and output variables based on available data from COMPUSTAT, we do not include some important intangible assets such as brand values. However, an important objective of corporate advertising is to build and strengthen brands, with the end goal of increasing revenues. Because we include advertising costs as an input to calculate the frontier-based efficiency measures, we believe that we have indirectly accounted for the impact of brands on revenues, our output measure.

10. In constructing our output and input variables, we require nonmissing values for revenue, PP\&E, COGS, and SG\&A.

11. The DEA-based Malmquist index requires balanced panel data (Villano, Fleming, Farrell, and Fleming 2006). However, requiring each observation to exist throughout the entire analysis period would greatly reduce the sample size. Thus, as an alternative approach, we created balanced subpanels using rolling twoyear periods (Cummins et al. 1999). 
industry ensures that firms in the estimation group have similar cost or production functions. For example, the relation between inputs and outputs for the computer industry is plausibly very different from that for business services.

To test the association between efficiency changes and profitability changes (Hypotheses $1 \mathrm{~A}$ and $1 \mathrm{~B}$ ), we adopt an approach that is similar to that used in prior research that has examined the persistence of changes in efficiency and financial ratios for future profitability changes (see, e.g., Abarbanell and Bushee 1997; Fairfield and Yohn 2001; Soliman 2008) and estimate the following OLS regression models:

$$
\begin{aligned}
\triangle R N O A_{t}= & \alpha+\beta_{1} \text { MALM }_{t}+\beta_{2} \text { RNOA }_{t}+\beta_{3} \Delta P M_{t}+\beta_{4} \Delta A T O_{t} \\
& +\sum_{i=1}^{9} \kappa_{i} \text { Fundamental signals }_{t}+\text { industry indicators }+\varepsilon \\
\triangle \text { RNO }_{t+1}= & \alpha+\beta_{1} \text { MALM }_{t}+\beta_{2} \text { RNOA }_{t}+\beta_{3} \Delta P M_{t}+\beta_{4} \Delta A T O_{t}+\beta_{5} \Delta R N O A_{t} \\
& +\sum_{i=1}^{9} \kappa_{i} \text { Fundamental signal }_{t}+\text { industry indicators }+\varepsilon
\end{aligned}
$$

$M A L M_{t}$ is either the Malmquist index estimated from DEA $\left(M A L M_{-} D E A_{t}\right)$ or SFA $\left(M A L M_{-} S F A_{t}\right)$. Return on net operating assets $\left(R N O A_{t}\right)$ is operating income divided by lagged net operating assets (NOA). Change in current RNOA $\left(\triangle R N O A_{t}\right)$ is $R N O A_{t}-$ $R N O A_{t-1}$. We decompose $\triangle R N O A_{t}$ into its components of profit margin $\left(P M_{t}\right)$ and asset turnover $\left(A T O_{t}\right)$. Changes in current profit margin $\left(\triangle P M_{t}\right)$ and asset turnover $\left(\triangle A T O_{t}\right)$ is $\left(P M_{t}-P M_{t-1}\right)$ and $\left(A T O_{t}-A T O_{t-1}\right)$, respectively. Recall from our earlier discussion that we are most interested in understanding how efficiency changes derived from frontier analysis compare to $\triangle A T O$, which prior research has shown to be related to future profitability changes. Change in future RNOA $\left(\triangle R N O A_{t+1}\right)$ is $R N O A_{t+1}-R N O A_{t}$.

Abarbanell and Bushee (1997) show that fundamental signals in year $t$ are related to earnings changes in year $t+1$. Consequently, we include the following nine fundamental signals from Abarbanell and Bushee 1997: inventory $\left(I N V_{t}\right)$, accounts receivable $\left(A R_{t}\right)$, capital expenditures $\left(C A P E X_{t}\right)$, gross margin $\left(G M A R G I N_{t}\right)$, selling and administrative expenses $\left(S G A_{t}\right)$, effective tax rate $\left(E F F T A X_{t}\right)$, labor force $\left(L A B O R_{t}\right)$, an indicator for earnings quality $\left(\right.$ LIFO $\left._{t}\right)$, and audit qualification $\left(O P I N I O N_{t}\right)$. Following Abarbanell and Bushee 1997, we construct each fundamental signal so that a negative (positive) sign on the signal indicates good (bad) news. For example, in the case of inventory, an increase in inventory exceeding sales growth is bad news. For brevity of exposition, we provide a more detailed description of the fundamental signals in Appendix 3. Finally, we also include industry indicators in the model to control for any industry fixed effects. To the extent that efficiently managed firms report higher current or future profitability, we expect the coefficient on $M A L M_{t}$ to be positive in (1) and (2).

To test whether efficiency changes convey value relevant information to market participants (Hypothesis 2A), we regress contemporaneous returns $\left(R E T_{t}\right)$ on our efficiency measures and control variables, as shown in (3). $R E T_{t}$ is defined as the 12-month buyand-hold return minus the stock's corresponding benchmark portfolio return according to firm size, book-to-market ratio, and momentum (Daniel, Grinblatt, Titman, and Wermers 1997; Wermers 2003) to directly control for firm characteristics known to affect stock returns. We construct the benchmarks from 125 portfolios on the basis of firm size, book-to-market ratio, and momentum. The return cumulation period begins 3 months after the start of the current fiscal year. $E A R N_{t}$ is the firm's earnings per share (EPS) in 
year $t$, deflated by stock price at the end of year $t-1 . \triangle E A R N_{t}$ is changes in EPS, deflated by stock price at the end of year $t-1$. All other variables are as previously defined. Our regression (3) is similar to that used in previous studies on operational efficiency (e.g., Fairfield and Yohn 2001; Soliman 2008).

$$
\begin{aligned}
\text { RET }_{t}= & \alpha+\beta_{1} \text { MALM }_{t}+\beta_{2} E_{A R N_{t}}+\beta_{3} \Delta E A R N_{t}+\beta_{4} R_{N O A_{t}}+\beta_{5} \Delta R N O A_{t} \\
& +\beta_{6} P_{t}+\beta_{7} A T O_{t}+\beta_{8} \Delta P M_{t}+\beta_{9} \Delta A T O_{t} \\
& +\sum_{i=1}^{9} \kappa_{i} \text { Fundamental signals }_{t}+\text { industry indicators }+\varepsilon
\end{aligned}
$$

We investigate whether equity investors fully impound information in efficiency changes (Hypothesis 2B) by estimating (4). $R E T_{t+1}$ is defined as the 12-month buy-andhold return minus the characteristic-based benchmark portfolio return (Daniel et al. 1997; Wermers 2003), measured beginning 3 months after the end of the current fiscal year. All other variables are as previously defined.

$$
\begin{aligned}
\text { RET }_{t+1}= & \alpha+\beta_{1} \text { MALM }_{t}+\beta_{2} \Delta R N O A_{t}+\beta_{3} \Delta P M_{t}+\beta_{4} \Delta A T O_{t}+\beta_{5} R_{N O A_{t}} \\
& +\beta_{6} P_{t}+\beta_{7} A T O_{t}+\sum_{i=1}^{9} \kappa_{i} \text { Fundamental signals }_{t} \\
& + \text { industry indicators }+\varepsilon
\end{aligned}
$$

We next investigate whether analysts' forecast revisions reflect the predictive information in future profitability changes (Hypothesis 3A) by estimating (5). Following Soliman 2008 , we construct one-year-ahead forecast revisions $\left(R E V_{t+1}\right)$, measured as the revision to the consensus (median) analyst forecast of year $t+1$ earnings made just after year $t$ earnings are announced. We also include the forecast error (or earnings surprise) in year $t$ $\left(F E_{t}\right)$, which is actual earnings for year $t$ minus the analyst earnings forecast scaled by stock price. All other variables are as previously defined.

$$
\begin{aligned}
R E V_{t+1}= & \alpha+\beta_{1} \text { MALM }_{t}+\beta_{2} F E_{t}+\beta_{3} \Delta R N O A_{t}+\beta_{4} \Delta P M_{t} \\
& +\beta_{5} \Delta A T O_{t}+\sum_{i=1}^{9} \kappa_{i} \text { Fundamental signals }_{t} \\
& + \text { industry indicators }+\varepsilon
\end{aligned}
$$

Finally, to assess whether analysts completely use the information contained in efficiency changes for future profitability changes (Hypothesis $3 \mathrm{~B}$ ), we examine the relation between $M A L M_{t}$ and future forecast errors $\left(F E_{t+1}\right)$ by estimating (6). We define forecast errors as actual earnings for year $t+1$ from $\mathrm{I} / \mathrm{B} / \mathrm{E} / \mathrm{S}$ minus the consensus forecast (median) from the month prior to the announcement of $t+1$ earnings, scaled by stock price at the end of the month of the earnings announcement for year $t .{ }^{12}$ We also control for potential serial correlation in forecast errors by including the prior period forecast error $\left(F E_{t}\right)$. All other variables are as previously defined.

12. We use the signed forecast error rather than its absolute value because our focus is on whether analysts fully understand the implication of the information in efficiency changes. That is, our aim is to assess whether analysts fully impound information from efficiency changes or whether they under- or over-react to this information. In contrast, using the absolute value of the forecast for this test does not provide such evidence. Our use of signed forecast errors agrees with the literature on analysts' efficiency (e.g., Abarbanell and Bushee 1997; Bradshaw et al. 2001; Rajgopal et al. 2003; Soliman 2008; Weber 2009; Simpson 2010). 
TABLE 1

Sample selection reconciliation

Number of observations

Firm-year observations with nonmissing input and output

156,838

variables on COMPUSTAT (1976-2008)

After making a two-year balanced panel for the estimation

of the DEA-based Malmquist index

After requiring a minimum of 20 observations per industry-year

group (MALM_DEA $A_{t}$ is available for this sample)

After requiring changes in current and future RNOA, nine

fundamental signals, and other controls

After requiring current and future returns

After deleting observations with stock price less than $\$ 1$

71,733

(Final sample for changes in RNOA and return regressions)

\section{Note:}

This table shows the sample selection reconciliation for our changes in RNOA and return regressions for the sample period 1976-2008.

$$
\begin{aligned}
F E_{t+1}= & \alpha+\beta_{1} M A L M_{t}+\beta_{2} F E_{t}+\beta_{3} \Delta R N O A_{t}+\beta_{4} \Delta P M_{t}+\beta_{5} \Delta A T O_{t}+\beta_{6} P M_{t} \\
& +\beta_{7} A T O_{t}+\sum_{i=1}^{9} \kappa_{i} \text { Fundamental signals }_{t}+\text { industry indicators }+\varepsilon
\end{aligned}
$$

\section{Data}

Table 1 describes the sample selection reconciliation. Our initial sample includes firm-years listed on the COMPUSTAT XPF files for the years $1976-2008 .{ }^{13}$ We follow prior research and exclude financial services and utilities firms from the sample. We start with firm-years with nonmissing input and output variables on COMPUSTAT. To estimate our efficiency measures, we drop firm-years in which there are fewer than 20 observations for each yearindustry combination. ${ }^{14} \mathrm{We}$ also require that firm-year observations have necessary data to compute the nine fundamental signals and other variables used in the regressions. For the profitability changes and returns regressions, we use 71,733 firm-year observations for the sample period 1976-2008. For the analyses using analysts' forecasts, we use the sample period starting from 1990 because coverage on $\mathrm{I} / \mathrm{B} / \mathrm{E} / \mathrm{S}$ is limited for earlier years and there are concerns about the reliability of earlier $\mathrm{I} / \mathrm{B} / \mathrm{E} / \mathrm{S}$ data (Bradshaw and Sloan 2002). ${ }^{15}$ As a result, we utilize 24,811 firm-year observations for the regressions of analysts' forecast revisions and forecast errors. ${ }^{16}$ To mitigate the effect of outliers, we winsorize variables at the bottom and top 1 percentiles of their distributions.

13. COMPUSTAT data for the year 2009 is also used in constructing one-year-ahead profitability changes.

14. The total number of estimation groups (industry-year) for the calculation of our efficiency measures over our sample period is 1,158 , and the mean (median) of number of observations in each estimation group is 133 (97) (untabulated).

15. The tenor of results is unchanged when using $\mathrm{I} / \mathrm{B} / \mathrm{E} / \mathrm{S}$ data for the years 1976-2008 (untabulated).

16. Demerjian et al. (2012) estimate the DEA score for about 177,000 firm-year observations for the period 1980-2009. This sample size is comparable to our initial sample with nonmissing input and output variables on COMPUSTAT for the period 1976-2008. Please see panel A of Table 1 for our sample selection reconciliation. 


\section{Empirical results}

\section{Descriptive statistics}

Table 2 provides descriptive statistics for the variables used in the regression analyses. The mean MALM_DEA $A_{t}\left(M A L M_{-} S F A_{t}\right)$ is $1.0(0.99)$, suggesting little change in the average efficiency of our sample. ${ }^{17,18}$ However, one standard deviation from the mean of $M A L$ $M \_D E A_{t}\left(M A L M_{-} S F A_{t}\right)$ is equal to a change of 10.8 percent (6.6 percent) in efficiency. Additionally, the interquartile range for $M A L M_{-} D E A_{t}\left(M A L M_{-} S F A_{t}\right)$ is 6 percent $(2.9$ percent). We therefore believe that there is sufficient variation in our efficiency measures to test our hypotheses. ${ }^{19}$ The mean values of the level of efficiency measures derived from DEA $\left(E F F_{-} D E A_{t}\right)$ and SFA $\left(E F F \_S F A_{t}\right)$ are 0.79 and 0.83 , respectively. Compared to other studies using a large sample, these average efficiency scores are slightly higher than the mean of DEA efficiency (0.57) in Demerjian et al. 2012, and similar to the mean value (0.75) in Leverty and Qian 2010. We also report that both technical efficiency changes $\left(E F F C H \_D E A_{t}\right.$ and EFFCH_SFA $\left.A_{t}\right)$ and technology changes (TECCH_DEA $A_{t}$ and TEC$C H \_S F A_{t}$ ) have a mean value close to one, while technical efficiency change has a larger standard deviation than technology change.

To provide the reader with some intuition about the frontier-based measures, we arbitrarily selected from the computer industry an efficient firm (Dell) and an inefficient firm (Data General Corp.), and compared some of their performance measures during a period when the computer industry experienced strong growth. Dell is well known for its efficient manufacturing system and direct sales to customers (Maney 2003). Dell's DEA score increased from 0.81 in 1990 to 1 in 1997. During the 1990-1997 period, Dell's ROA increased from 15.9 percent to 31.5 percent and its stock price increased from $\$ 23$ to $\$ 99$. On the other hand, Data General's DEA score was 0.69 in 1990 and declined to 0.62 in 1993. Over the same period, Data General's ROA decreased from 9.4 percent to -6.4 percent, and its stock price fell from $\$ 20$ to $\$ 10$.

Table 2 also shows that the mean (median) current change in RNOA $\left(\triangle R N O A_{t}\right)$ is $-0.012(-0.001)$ and the mean (median) future change in RNOA $\left(\triangle R N O A_{t+1}\right)$ is -0.020 $(-0.004){ }^{20}$ The mean (median) characteristic-adjusted contemporaneous return $\left(R E T_{t}\right)$ is 0.2 percent $(-6.9 \%)$, while the mean (median) characteristic-adjusted one-year-ahead return $\left(R E T_{t+1}\right)$ is -1.9 percent $(-7.7 \%)$.

17. Matching our arguments, the first-order autocorrelation of the DEA (SFA) score is 0.84 (0.90) (untabulated), indicating persistence in the score over time.

18. Studies using the Malmquist index highlight that periods of efficiency improvements alternate with periods of efficiency decline and that the pattern of changes in efficiency varies across industries. For example, Chen and Ali (2004) report that the computer industry experienced deterioration in efficiency for half of their sample period, while it showed an improvement in efficiency for the other half of their sample period. Furthermore, Shestalova (2003) documents that innovations in efficiency vary across industries over the period 1970-1990. Our sample spans several decades and includes a variety of industries. Thus, the small average change in efficiency for our sample corresponds with the canceling out effect highlighted in prior research. Although small efficiency changes for a specific time period or for some industries may be counterintuitive given the development of technology over time, Berger and Mester (1997) provide several plausible explanations for this outcome: (i) industrial competition has become more intense over time, leading to higher operating costs and lower margins; (ii) firms need increasingly larger investments to adopt new technology; and (iii) increased regulation and other external events can affect average industry efficiency.

19. Other studies also report relatively little variation in the Malmquist index. For example, Cummins et al. (1999) report that the standard deviation of the Malmquist index is 3.3 percent for M\&A target firms and 0.9 percent for nontarget firms for the U.S. life insurance industry. Odeck (2006) reports that the standard deviation of the Malmquist index is 1.4 percent for traffic safety services.

20. Soliman (2008) similarly reports a mean $\triangle R N O A_{t}$ of 0.00 with a standard deviation of 0.431 . 
TABLE 2

Descriptive statistics

\begin{tabular}{|c|c|c|c|c|c|c|c|}
\hline Variable & Mean & Std. Dev. & Min & Q1 & Median & Q3 & Max \\
\hline$I N V_{t}$ & 0.055 & 0.770 & -2.431 & -0.202 & -0.024 & 0.164 & 5.729 \\
\hline$A R_{t}$ & 0.020 & 0.450 & -2.401 & -0.142 & -0.009 & 0.127 & 3.532 \\
\hline$C A P E X_{t}$ & -0.282 & 1.355 & -11.309 & -0.483 & 0.010 & 0.379 & 1.213 \\
\hline$G_{M A R G I N_{t}}$ & 0.002 & 0.387 & -2.987 & -0.068 & -0.001 & 0.070 & 6.141 \\
\hline$S G A_{t}$ & -0.002 & 0.276 & -2.320 & -0.080 & 0.005 & 0.091 & 1.258 \\
\hline EFFTAX $X_{t}$ & -0.004 & 0.076 & -0.514 & -0.002 & 0.000 & 0.001 & 0.398 \\
\hline$L I F O_{t}$ & 0.779 & 0.415 & 0.000 & 1.000 & 1.000 & 1.000 & 1.000 \\
\hline OPINION $_{t}$ & 0.228 & 0.419 & 0.000 & 0.000 & 0.000 & 0.000 & 1.000 \\
\hline$L A B O R_{t}$ & -0.085 & 0.285 & -3.183 & -0.150 & -0.057 & 0.027 & 0.712 \\
\hline$E F F_{-} D E A_{t}$ & 0.790 & 0.162 & 0.008 & 0.720 & 0.822 & 0.900 & 1.000 \\
\hline$E F F \_S F A_{t}$ & 0.830 & 0.102 & 0.004 & 0.784 & 0.853 & 0.902 & 0.989 \\
\hline$M A L M_{-} D E A_{t}$ & 1.000 & 0.108 & 0.540 & 0.970 & 1.000 & 1.030 & 1.620 \\
\hline$M A L M \_S F A_{t}$ & 0.999 & 0.066 & 0.672 & 0.984 & 1.000 & 1.013 & 1.440 \\
\hline$E F F C H \_D E A_{t}$ & 1.015 & 0.155 & 0.460 & 0.960 & 1.000 & 1.050 & 1.920 \\
\hline$T E C C H \_D E A_{t}$ & 0.997 & 0.119 & 0.610 & 0.960 & 1.000 & 1.030 & 1.750 \\
\hline$E F F C H \_S F A_{t}$ & 0.999 & 0.066 & 0.675 & 0.984 & 1.000 & 1.012 & 1.444 \\
\hline TECCH_SFA & 1.000 & 0.006 & 0.974 & 0.997 & 0.999 & 1.002 & 1.028 \\
\hline$A T O_{t}$ & 3.019 & 2.871 & 0.139 & 1.575 & 2.303 & 3.430 & 29.018 \\
\hline$P M_{t}$ & 0.031 & 0.486 & -16.970 & 0.025 & 0.068 & 0.116 & 0.434 \\
\hline$\triangle A T O_{t}$ & -0.135 & 1.799 & -14.770 & -0.369 & -0.003 & 0.293 & 9.000 \\
\hline$\Delta P M_{t}$ & -0.003 & 0.208 & -3.048 & -0.021 & 0.000 & 0.018 & 4.634 \\
\hline$R N O A_{t}$ & 0.156 & 0.503 & -8.799 & 0.060 & 0.158 & 0.278 & 2.351 \\
\hline$\triangle R N O A_{t}$ & -0.012 & 0.402 & -3.105 & -0.075 & -0.001 & 0.058 & 3.832 \\
\hline$\triangle R N O A_{t+1}$ & -0.020 & 0.367 & -3.008 & -0.078 & -0.004 & 0.054 & 3.796 \\
\hline$E R A N_{t}$ & 0.032 & 0.187 & -1.503 & 0.010 & 0.055 & 0.101 & 0.484 \\
\hline$\triangle E A R N_{t}$ & 0.010 & 0.195 & -1.000 & -0.031 & 0.004 & 0.035 & 1.299 \\
\hline$R E T_{t}$ & 0.002 & 0.525 & -1.080 & -0.298 & -0.069 & 0.190 & 2.495 \\
\hline$R E T_{t+1}$ & -0.019 & 0.515 & -1.165 & -0.313 & -0.077 & 0.182 & 2.283 \\
\hline$R E V_{t+1}$ & -0.003 & 0.015 & -0.109 & -0.004 & 0.000 & 0.001 & 0.053 \\
\hline$F E_{t+1}$ & -0.005 & 0.041 & -0.390 & -0.002 & 0.000 & 0.002 & 0.120 \\
\hline$F E_{t}$ & -0.003 & 0.028 & -0.323 & -0.002 & 0.000 & 0.002 & 0.111 \\
\hline
\end{tabular}

Note:

This table reports descriptive statistics for the sample period 1976-2008. Note that the descriptive statistics for $R E V_{t+1}, F E_{t+1}$, and $F E_{t}$ are reported for the sample period 1990-2008. See Appendix 3 for the definitions of the variables.

\section{Correlations}

Pearson correlations in panel A of Table 3 indicate that both $M A L M_{-} D E A_{t}$ and $M A L-$ $M_{-} S F A_{t}$ are positively correlated with current profitability changes at the 1 percent level, as expected. While $M A L M_{-} D E A_{t}$ and $M A L M_{-} S F A_{t}$ are negatively correlated with future profitability changes, these correlations are plausibly due to the negative relation between current and future profitability changes (i.e., mean reversion). ${ }^{21}$ That is, MALM is

21. In Table 2 of Soliman 2008, the correlation between $\triangle R N O A_{t+1}$ and $\triangle A T O_{t}$ is also negative and insignificant $(-0.002, p$-value $=0.68)$. 
TABLE 3

Correlations

Panel A: Correlations between changes in frontier-based efficiency changes and several dependent variables

\begin{tabular}{lcccccr}
\hline & $\Delta R N O A_{t}$ & $\Delta R N O A_{t+1}$ & $R E T_{t}$ & $R E T_{t+1}$ & $R E V_{t+1}$ & $F E_{t+1}$ \\
\hline MALM_DEA & 0.42 & -0.01 & 0.23 & 0.02 & 0.06 & 0.05 \\
MALM_SFA & 0.42 & -0.01 & 0.20 & 0.03 & 0.07 & 0.05 \\
\hline
\end{tabular}

Panel B: Correlations between changes in frontier-based efficiency measures and changes in other efficiency measures

\begin{tabular}{|c|c|c|c|c|c|}
\hline & $M A L M \_S F A_{t}$ & $\triangle S I Z E_{t}$ & $\triangle A T O_{t}$ & $\triangle P_{P E T O}$ & $\triangle E M P_{-} P_{t}$ \\
\hline$M A L M \_D E A_{t}$ & 0.82 & 0.28 & 0.29 & 0.37 & 0.39 \\
\hline MALM_SFA & & 0.25 & 0.20 & 0.14 & 0.28 \\
\hline$\triangle S I Z E_{t}$ & & & 0.18 & 0.16 & 0.20 \\
\hline$\triangle A T O_{t}$ & & & & 0.39 & 0.32 \\
\hline$\triangle P P E T O_{t}$ & & & & & 0.40 \\
\hline
\end{tabular}

Notes:

Panel A reports the Pearson correlation coefficients between frontier-based efficiency changes and several dependent variables used in our analyses. Panel B reports the Pearson correlation coefficients between measures of operational efficiency. All variables are defined in Appendix 3.

All correlations are significant at the 1 percent level.

strongly and positively correlated with current profitability changes, which are negatively correlated with future profitability changes. ${ }^{22}$ In addition, $M A L M_{-} D E A_{t}$ and $M A L-$ $M \_S F A_{t}$ are positively correlated with current and future stock returns ( $p$-values $\left.<0.01\right)$, as well as with analyst forecast revisions and analyst forecast errors. Overall, except for the correlations between MALM and future profitability changes, the findings in panel A of Table 3 provide univariate evidence that efficiency changes based on frontier analysis are positively related to firm performance.

Before we execute our regression analyses, we first assess whether our frontier-based efficiency measures are valid constructs for firm's operational efficiency by analyzing the correlations with other commonly used efficiency measures. We examine the correlation between our frontier-based efficiency measures and firm size (Jovanovic 1982), asset turnover, PP\&E turnover, and employee productivity. ${ }^{23}$ In panel $\mathrm{B}$ of Table 3, we report that the correlation between MALM_DEA $\left(M A L M_{-} S F A_{t}\right)$ and $\triangle A T O_{t}$ is $0.29(0.20)$ and that the correlations between MALM and both PP\&E turnover and employee productivity are positive, suggesting that our efficiency measures and changes in asset turnover contain overlapping but different information. These results help to mitigate the concern that a high correlation between the frontier-based measures and a simple ratio (such as asset turnover) eliminates the need for weighting multiple variables, which is a considerable advantage of frontier-based measures over simple financial ratios. We next conduct multiple regression analyses to test the relation between our efficiency measures and measures of changes in firm performance.

22. Subramanyam and Venkatachalam (2007, footnote 19) provide a similar explanation for the negative correlation between current accruals and future operating cash flows.

23. Untabulated correlations between industry-adjusted variables and levels of the variables are similar to those reported. 
TABLE 4

Regressions of current changes in RNOA on efficiency changes

\begin{tabular}{|c|c|c|c|c|}
\hline & \multirow[b]{2}{*}{ Predicted } & \multicolumn{3}{|c|}{ Dependent variable $=\Delta R N O A_{t}$} \\
\hline & & (1) & $\underset{(2)}{M A L M_{-} D E A_{t}}$ & $\underset{\text { (3) }}{M A L M_{-} S F A_{t}}$ \\
\hline Intercept & & $-0.032 * * *(<.0001)$ & $-0.697 * * *(<.0001)$ & $-1.362 * * *(<.0001)$ \\
\hline$M A L M_{t}$ & $(+)$ & & $0.669 * * *(<.0001)$ & $1.333^{* * * *(<.0001)}$ \\
\hline$R N O A_{t}$ & $(+)$ & $0.142 * * *(<.0001)$ & $0.139 * * *(<.0001)$ & $0.139 * * *(<.0001)$ \\
\hline$\Delta P M_{t}$ & $(+)$ & $0.379 * * *(<.0001)$ & $0.254 * * *(0.00)$ & $0.147 *(0.08)$ \\
\hline$\triangle A T O_{t}$ & $(+)$ & $0.066^{* * *}(<.0001)$ & $0.060 * * *(<.0001)$ & $0.063^{* * *}(<.0001)$ \\
\hline$I N V_{t}$ & $?$ & $-0.005(0.27)$ & $-0.003(0.52)$ & $-0.003(0.50)$ \\
\hline$A R_{t}$ & $?$ & $0.002(0.78)$ & $-0.003(0.67)$ & $-0.001(0.92)$ \\
\hline$C A P E X_{t}$ & $?$ & $0.011 * * *(<.0001)$ & $0.012 * * *(<.0001)$ & $0.009 * * *(<.0001)$ \\
\hline GMARGIN $_{t}$ & $?$ & $-0.118 * * *(<.0001)$ & $-0.084 * * *(<.0001)$ & $-0.068 * * *(<.0001)$ \\
\hline$S G A_{t}$ & $?$ & $-0.278^{* * *}(<.0001)$ & $-0.175^{* * *}(<.0001)$ & $-0.195^{* * *}(<.0001)$ \\
\hline EFFTAX $X_{t}$ & $?$ & $-0.010(0.57)$ & $-0.022(0.23)$ & $-0.033(0.12)$ \\
\hline$L_{L I F O}$ & $?$ & $0.006^{* *}(0.02)$ & $0.005 * *(0.02)$ & $0.006^{* * *}(0.01)$ \\
\hline OPINION $_{t}$ & $?$ & $0.017 * *(0.03)$ & $0.016 * *(0.03)$ & $0.017 * *(0.04)$ \\
\hline$L A B O R_{t}$ & $?$ & $-0.047 * * *(0.00)$ & $-0.034 * *(0.00)$ & $-0.038 * * *(0.00)$ \\
\hline Industry indicators & & Yes & Yes & Yes \\
\hline Average adj. $R^{2}$ & & $38.76 \%$ & $40.90 \%$ & $41.37 \%$ \\
\hline
\end{tabular}

\section{Notes:}

This table reports the time-series cross-sectional regression estimates of current changes in RNOA on frontier-based efficiency changes and controls. The $p$-values in parentheses are based on Fama-MacBeth 1973 standard errors with the Newey-West 1987 adjustment. See Appendix 3 for the definitions of the other variables. The sample is 71,733 observations for the period 1976 -2008 . All tests are two-tailed. The symbols *,**, and *** denote significance at the $0.1,0.05$, and 0.01 levels, respectively.

\section{Efficiency changes and profitability changes}

We use (1) to test the relation between efficiency changes and current profitability changes (Hypothesis 1A) and report the results in Table $4 .{ }^{24,25}$ In column 1, we first establish whether our sample provides results similar to those in prior research by regressing current profitability changes on $\triangle A T O_{t}, \triangle P M_{t}$, previous profitability changes, and the fundamental signals from Abarbanell and Bushee 1997. The coefficient on $\triangle A T O_{t}$ is positive and significant, consistent with prior research (Nissim and Penman 2001; Penman and Zhang 2003). There is also a highly significant and positive coefficient on $\triangle P M_{t}$. In column 2 , we regress current profitability changes on $M A L M_{-} D E A_{t}, \triangle A T O_{t}, \triangle P M_{t}$, and control variables. The coefficient on $M A L M \_D E A_{t}$ is a significant 0.669 ( $p$-value $<0.001$ ), even after controlling for current profitability and various fundamental signals. This result indicates that firms with efficiency improvement enjoy an increase in contemporaneous profitability. The coefficients on $G M A R G I N_{t}, S G A_{t}, L A B O R_{t}$, and $L I F O_{t}$ are negative and significant, while the coefficients on $C A P E X_{t}, L I F O_{t}$, and $O P I N I O N_{t}$ are positive and significant. In the next set of regressions in Table 4, we replace $M A L M_{-} D E A_{t}$ with $M A L M_{-} S F A_{t}$ and

24. None of the variance inflation factors in any of the regressions in our paper exceeds 3 (untabulated). Thus, multicollinearity does not likely affect our results.

25. We estimate the primary regressions in our paper cross-sectionally and report the average coefficients, with the Fama-MacBeth 1973 t-statistics adjusted for serial correlation using the Newey-West 1987 method. 
find similar results to those using $M A L M_{-} D E A_{t}$. These results highlight the incremental importance of MALM_DEA $A_{t}$ and $M A L M_{-} S F A_{t}$ compared to other determinants of profitability changes used in prior studies.

We next assess the economic significance of the results in Table 4. To do so, we follow Hirshleifer, Hou, and Teoh 2009 and standardize the independent variables to have zero mean and unit variance. Doing so makes the coefficients comparable because the coefficient on a standardized variable represents the effect of a one standard deviation change in the independent variable on the dependent variable. Untabulated results indicate that the coefficient of $0.072(0.088)$ on standardized MALM_DEA $\left(M A L M_{-} S F A_{t}\right)$ is highly significant in both statistical and economic terms. For example, a one standard deviation change in MALM_DEA $A_{t}$ is associated with an increase of 7.2 percent in current profitability changes. These results highlight that our efficiency measures provide information that is incremental to efficiency measures based on simple financial ratios. Additionally, adding $M A L M_{-} D E A_{t}\left(M A L M_{-} S F A_{t}\right)$ to the baseline regression (column 1) significantly increases adjusted $R^{2}$ from 38.76 percent to 40.90 percent $(41.37$ percent) $(p$-values $<0.01)$. This finding suggests that MALM adds further explanatory power to the regression.

Overall, the results based on the multivariate models in Table 4 correspond with the univariate relations between efficiency changes and current profitability changes. These results support the notion that efficiency changes based on frontier analysis are important in explaining current profitability changes, even after controlling for simple financial ratios known to affect current profitability changes.

We use (2) to examine whether efficiency changes are associated with future profitability changes (Hypothesis 1B). We report results in Table 5. To benchmark against prior research, we regress $\triangle R N O A_{t+1}$ on $\triangle A T O_{t}$ and other controls. Column 1 shows that the coefficient on $\triangle A T O_{t}$ is positive and significant, suggesting that changes in asset turnover are related to higher future profitability (Fairfield and Yohn 2001). The coefficient on $\triangle R N O A_{t}$ is negative and significant (Soliman 2008). In column 2, we include $M A L$ $M_{-} D E A_{t}$ and find that its coefficient is positive and significant at the 1 percent level, supporting the notion that efficiency changes based on frontier analysis in the current period are informative about future profitability changes. Several control variables such as $I N V_{t}$, $L I F O_{t}$, and $O P I N I O N_{t}$ show significant results with the predicted sign. The coefficient on $C A P E X_{t}$ is positive, suggesting that an increase in capital expenditures in excess of the industry is bad news, partly due to the immediate effect of increased depreciation (Abarbanell and Bushee 1997). In column 3, we report results for $M A L M_{-} S F A_{t}$ that are similar to those for MALM_DEA .

To assess the economic significance of $M A L M_{-} D E A_{t}\left(M A L M_{-} S F A_{t}\right)$, we standardize the independent variables as described above. Untabulated results indicate that the coefficient of $0.013(0.010)$ on standardized $M A L M_{-} D E A_{t}\left(M A L M_{-} S F A_{t}\right)$ is statistically and economically significant. That is, a one standard deviation change in $M A L M_{-} D E A_{t}$ is associated with more than a 1.3 percent increase in future profitability changes. We also find that the coefficient on standardized $M A L M_{-} D E A_{t}\left(M A L M_{-} S F A_{t}\right)$ is slightly greater than the coefficient of 0.009 (0.010) on standardized $\triangle A T O_{t}$. Additionally, adding $M A L$ M_DEA $A_{t}$ (MALM_SFA $A_{t}$ ) to the baseline regression increases the adjusted $R^{2}$ from 18.26 percent to 18.48 percent (18.48 percent), which is significant at the 1 percent level. This result suggests that our efficiency measures add further explanatory power to the regressions.

The relation between changes in future profitability and changes in efficiency may not be linear. To assess this issue, we conduct a portfolio test for future profitability changes by sorting the sample by changes in efficiency. Because changes in current profitability are important for predicting future profitability changes (Table 5) and because changes in profitability tend to mean-revert, we double-sort the sample by both current profitability 
TABLE 5

Regressions of one-year-ahead changes in RNOA on efficiency changes

\begin{tabular}{|c|c|c|c|c|}
\hline & \multirow[b]{2}{*}{ Predicted } & \multicolumn{3}{|c|}{ Dependent variable $=\triangle R N O A_{t+1}$} \\
\hline & & (1) & $\underset{(2)}{M A L M_{-}} D E A_{t}$ & MALM_SFA \\
\hline Intercept & ? & $0.053 * * *(<.0001)$ & $-0.068 *(0.07)$ & $-0.100(0.14)$ \\
\hline$M A L M_{t}$ & $(+)$ & & $0.121 * * *(0.00)$ & $0.153 * *(0.02)$ \\
\hline$R N O A_{t}$ & $(-)$ & $-0.257 * * *(<.0001)$ & $-0.257 * * *(<.0001)$ & $-0.257 * * *(<.0001)$ \\
\hline$\Delta P M_{t}$ & $(+)$ & $0.084 * * *(0.00)$ & $0.051(0.18)$ & $0.052(0.14)$ \\
\hline$\triangle A T O_{t}$ & $(+)$ & $0.006^{* *}(0.03)$ & $0.005 *(0.07)$ & $0.006 * *(0.04)$ \\
\hline$\triangle R N O A_{t}$ & $(-)$ & $-0.071^{* * *}(0.00)$ & $-0.077 * * *(<.0001)$ & $-0.075^{* * *}(0.00)$ \\
\hline$I N V_{t}$ & $(-)$ & $-0.016^{* * *}(<.0001)$ & $-0.016^{* * *}(<.0001)$ & $-0.015^{* * *}(<.0001)$ \\
\hline$A R_{t}$ & $?$ & $0.003(0.56)$ & $0.003(0.62)$ & $0.003(0.59)$ \\
\hline$C A P E X_{t}$ & $?$ & $0.013^{* * *}(<.0001)$ & $0.014 * * *(<.0001)$ & $0.013^{* * *}(<.0001)$ \\
\hline GMARGIN $_{t}$ & $(-)$ & $0.004(0.66)$ & $0.009(0.29)$ & $0.008(0.32)$ \\
\hline$S G A_{t}$ & $(-)$ & $-0.020 *(0.07)$ & $-0.005(0.68)$ & $-0.012(0.32)$ \\
\hline EFFTAX $X_{t}$ & $(-)$ & $0.008(0.67)$ & $0.006(0.73)$ & $0.006(0.74)$ \\
\hline $\mathrm{LIFO}_{t}$ & $(-)$ & $-0.014 * * *(0.00)$ & $-0.014 * * *(0.00)$ & $-0.014 * * *(0.00)$ \\
\hline OPINION $_{t}$ & $(-)$ & $-0.016 * *(0.02)$ & $-0.017 * *(0.02)$ & $-0.016 * *(0.02)$ \\
\hline$L A B O R_{t}$ & $(-)$ & $0.014(0.12)$ & $0.017 *(0.06)$ & $0.015^{*}(0.09)$ \\
\hline Industry indicators & & Yes & Yes & Yes \\
\hline Average adj. $R^{2}$ & & $18.26 \%$ & $18.48 \%$ & $18.48 \%$ \\
\hline
\end{tabular}

\section{Notes:}

This table reports the time-series cross-sectional regression estimates of one-year-ahead changes in RNOA on frontier-based efficiency changes and controls. The $p$-values in parentheses are based on Fama-MacBeth 1973 standard errors with the Newey-West 1987 adjustment. See Appendix 3 for the definitions of the other variables. The sample is 71,733 observations for the period 1976-2008. All tests are two-tailed. The symbols *,**, and *** denote significance at the $0.1,0.05$, and 0.01 levels, respectively.

changes $\left(\triangle R N O A_{t}\right)$ and changes in efficiency. Table 6 reports the time-series means of one-year-ahead profitability changes for $M A L M_{-} D E A_{t}, M A L M_{-} S F A_{t}$, and $\triangle A T O_{t}$. For example, for the lowest $\triangle R N O A_{t}$ group (T1), the difference between Q4 and Q1 is 4.4 percent and 7.5 percent for $M A L M_{-} D E A_{t}$ and $M A L M_{-} S F A_{t}$, respectively. Overall, results indicate that the difference between the highest quartile $(\mathrm{Q} 4)$ and lowest quartile $(\mathrm{Q} 1)$ of MALM_DEAt and MALM_SFA $A_{t}$ is positive and significant across quartiles of $\triangle R N O A_{t}$. In comparison, the results for $\triangle A T O_{t}$ are mixed, as evidenced by the negative values for the second and third portfolios by $\triangle R N O A_{t}$. In sum, the evidence in Table 6 suggests a linear relation between changes in future profitability and changes in our efficiency measures.

Overall, the findings in Tables 4 through 6 suggest that changes in frontier-based efficiency measures are informative about current and future profitability changes, even after controlling for other documented predictors of profitability such as fundamental signals (Abarbanell and Bushee 1997) and changes in asset turnover (Fairfield and Yohn 2001; Soliman 2008). Additionally, we show that these findings are economically significant. Our findings thus provide an important contribution by highlighting that frontierbased efficiency measures improve profitability forecasts. Whether market participants use this information is the focus of tests performed below. 
TABLE 6

Time-series means of one-year-ahead changes in RNOA by changes in efficiency portfolios after controlling for current changes in RNOA

Panel A: Quartiles by $M A L M_{-} D E A_{t}$

Terciles by $\triangle R N O A_{t}$

\begin{tabular}{lll}
\hline $\mathrm{T} 1$ & $\mathrm{~T} 2$ & $\mathrm{~T} 3$
\end{tabular}

\begin{tabular}{lllll}
\hline Quintiles & Q1 & $-0.006(0.27)$ & $-0.023^{* * *}(0.00)$ & $-0.074 * * *(0.00)$ \\
& Q2 & $-0.029^{* * *}(<.0001)$ & $-0.014^{* * *}(0.00)$ & $-0.055^{* * *}(<.0001)$ \\
& Q3 & $-0.038^{* * *}(0.00)$ & $-0.008^{* *}(0.01)$ & $-0.034^{* * *}(<.0001)$ \\
Q4 & $0.037(0.17)$ & $-0.009(0.10)$ & $-0.034^{* * *}(0.00)$ \\
Difference (Q4 - Q1) & & $0.044^{*}(0.09)$ & $0.014 * *(0.04)$ & $0.040^{*}(0.06)$ \\
\hline
\end{tabular}

Panel B: Quartiles by $M A L M_{-} S F A_{t}$

Terciles by $\triangle R N O A_{t}$

\begin{tabular}{lcccc}
\cline { 3 - 4 } & & \multicolumn{1}{c}{$\mathrm{T} 1$} & $\mathrm{~T}$ & \multicolumn{1}{c}{$\mathrm{T} 3$} \\
\hline Quintiles & $\mathrm{Q} 1$ & $0.003(0.55)$ & $-0.020^{* * *}(0.00)$ & $-0.110^{* * *}(0.00)$ \\
& $\mathrm{Q} 2$ & $-0.046^{* * *}(<.0001)$ & $-0.016^{* * *}(<.0001)$ & $-0.092^{* * *}(<.0001)$ \\
& $\mathrm{Q} 3$ & $-0.054^{* * *}(0.00)$ & $-0.010^{* * *}(0.00)$ & $-0.043^{* * *}(<.0001)$ \\
Difference (Q4 - Q1) & & $0.078^{* *}(0.02)$ & $-0.001(0.91)$ & $-0.023^{* *}(0.02)$ \\
\hline
\end{tabular}

Panel C: Quartiles by $\triangle A T O_{t}$

Terciles by $\triangle R N O A_{t}$

Panel Q Quartiles by $\triangle A T O_{t}$

\begin{tabular}{ccl}
\multicolumn{3}{c}{ Terciles by $\triangle R N O A_{t}$} \\
\hline $\mathrm{T} 1$ & \multicolumn{1}{c}{$\mathrm{T} 2$} & \multicolumn{1}{c}{$\mathrm{T} 3$} \\
\hline$-0.039^{* * *}(<.0001)$ & $-0.011^{* *}(0.05)$ & $-0.007(0.61)$ \\
$-0.013^{* * *}(0.01)$ & $-0.010^{* * *}(0.01)$ & $-0.016^{* *}(0.04)$ \\
$0.003(0.67)$ & $-0.010^{* * *}(0.00)$ & $-0.002(0.77)$ \\
$0.129^{* * * *}(<.0001)$ & $-0.023^{* * *}(0.00)$ & $-0.066^{* * *}(<.0001)$ \\
$0.167^{* * *}(<.0001)$ & $-0.012^{*}(0.06)$ & $-0.059^{* * *}(0.00)$ \\
\hline
\end{tabular}

Notes:

This table presents the time-series average one-year-ahead changes in RNOA $\left(\triangle R N O A_{t+1}\right)$ for 12 portfolios by double-sorting on current changes in RNOA $\left(\triangle R N O A_{t}\right)$ and efficiency changes $\left(M A L M_{-} D E A_{t}, M A L M_{-} S F A_{t}\right.$, or $\left.\triangle A T O_{t}\right)$. The sample is 71,733 observations for the years 1976-2008. The $p$-values in parentheses are based on the time-series of annual portfolio values. All tests are two-tailed. The symbols $* * *$, and $* * *$ denote significance at the $0.1,0.05$, and 0.01 levels, respectively.

\section{Do equity investors impound the information in efficiency changes?}

Next, we provide evidence about whether equity investors impound into current returns the predictive information in efficiency changes about profitability changes (Hypothesis 2A). Table 7 presents the results of regressions in which the dependent variable is current characteristic-adjusted returns. ${ }^{26}$ In column 1, we first establish whether our sample exhib-

26. We also use market-adjusted returns and size-adjusted returns for both current and future returns models, leaving the tenor of results unchanged (untabulated). 
TABLE 7

Regressions of contemporaneous returns on efficiency changes

\begin{tabular}{|c|c|c|c|c|}
\hline & \multirow[b]{2}{*}{ Predicted } & \multicolumn{3}{|c|}{ Dependent variable $=R E T_{t}$} \\
\hline & & (1) & $\underset{(2)}{M A L M_{-} D E A_{t}}$ & $\underset{\text { (3) }}{M A L M_{S} S F A_{t}}$ \\
\hline Intercept & $?$ & $-0.079 * * *(0.00)$ & $-0.609 * * *(<.0001)$ & $-0.755^{* * *}(<.0001)$ \\
\hline$M A L M_{t}$ & $(+)$ & & $0.531 * * *(<.0001)$ & $0.677 * * *(<.0001)$ \\
\hline$E A R N_{t}$ & $(+)$ & $0.323 * * *(<.0001)$ & $0.332 * * *(<.0001)$ & $0.333^{* * * *}(<.0001)$ \\
\hline$\triangle E A R N_{t}$ & $(+)$ & $0.404 * * *(<.0001)$ & $0.360 * * *(<.0001)$ & $0.365^{* * *}(<.0001)$ \\
\hline$R N O A_{t}$ & $(+)$ & $0.090 * * *(<.0001)$ & $0.088 * * *(<.0001)$ & $0.088^{* * * *}(<.0001)$ \\
\hline$\triangle R N O A_{t}$ & $(+)$ & $0.118 * * *(<.0001)$ & $0.099 * * *(<.0001)$ & $0.104^{* * *}(<.0001)$ \\
\hline$P M_{t}$ & $(+)$ & $-0.008(0.82)$ & $0.000(1.00)$ & $-0.002(0.96)$ \\
\hline$A T O_{t}$ & $(+)$ & $0.004 * * *(0.00)$ & $0.004 * * *(0.00)$ & $0.004 * * *(0.00)$ \\
\hline$\Delta P M_{t}$ & $(+)$ & $-0.007(0.79)$ & $-0.125 * *(0.01)$ & $-0.132 * * *(0.01)$ \\
\hline$\triangle A T O_{t}$ & $(+)$ & $0.009 * * *(0.00)$ & $0.006 * *(0.01)$ & $0.009 * * *(0.00)$ \\
\hline$I N V_{t}$ & $(-)$ & $-0.012 * * *(<.0001)$ & $-0.011^{* * *}(<.0001)$ & $-0.012 * * *(<.0001)$ \\
\hline$A R_{t}$ & $(-)$ & $0.031 * * *(0.00)$ & $0.028 * * *(0.00)$ & $0.031 * * *(0.00)$ \\
\hline$C A P E X_{t}$ & $(-)$ & $-0.007 * * *(0.00)$ & $-0.006 * * *(0.00)$ & $-0.007 * * *(0.00)$ \\
\hline GMARGIN $_{t}$ & $(-)$ & $-0.097 * * *(<.0001)$ & $-0.077 * * *(<.0001)$ & $-0.076^{* * *}(<.0001)$ \\
\hline$S G A_{t}$ & $(-)$ & $-0.144 * * *(<.0001)$ & $-0.075^{* * *}(0.00)$ & $-0.112^{* * *}(<.0001)$ \\
\hline EFFTAX $X_{t}$ & $(-)$ & $-0.186^{* * *}(<.0001)$ & $-0.184 * * *(<.0001)$ & $-0.190 * * *(<.0001)$ \\
\hline$L I F O_{t}$ & $(-)$ & $0.012 * *(0.03)$ & $0.013 * *(0.03)$ & $0.013 * *(0.03)$ \\
\hline OPINION $_{t}$ & $(-)$ & $-0.039 * * *(<.0001)$ & $-0.039 * * *(<.0001)$ & $-0.038 * * *(<.0001)$ \\
\hline$L_{A B O R_{t}}$ & $(-)$ & $0.013(0.33)$ & $0.023 *(0.08)$ & $0.017(0.20)$ \\
\hline Industry indicators & & Yes & Yes & Yes \\
\hline Average adj. $R^{2}$ & & $17.56 \%$ & $18.07 \%$ & $17.87 \%$ \\
\hline
\end{tabular}

\section{Notes:}

This table reports the time-series cross-sectional regression estimates of contemporaneous characteristic-adjusted stock returns on frontier-based efficiency changes and controls. The $p$-values in parentheses are based on Fama-MacBeth 1973 standard errors with the NeweyWest 1987 adjustment. The dependent variable $\left(R E T_{t}\right)$ is computed by taking the 12 -month buy-and-hold return and subtracting the stock's corresponding benchmark portfolio return according to firm size, book-to-market ratio, and momentum. The return cumulation period begins 3 months after the beginning of the fiscal year. $M A L M_{t}$ in column 2 is the Malmquist index estimated from DEA, and $M A L M_{t}$ in column 3 is the Malmquist index estimated from SFA. See Appendix 3 for the definitions of the other variables. The sample is 71,733 observations for the period 1976-2008. All tests are two-tailed. The symbols *,**, and *** denote significance at the $0.1,0.05$, and 0.01 levels, respectively.

its similar results to those in prior research by regressing current returns on $\triangle A T O_{t}$ and other control variables. We report that the coefficient on $\triangle A T O_{t}$ is positive and significant ( $p$-value $<0.01$ ), implying that changes in asset turnover are value relevant to investors (Soliman 2008). We also report that $P M_{t}$ and $\Delta P M_{t}$ are not significant in the presence of other fundamental signals. In column 2, we include $M A L M_{-} D E A_{t}$ and control variables used in column 1. We report that the coefficient on $M A L M_{-} D E A_{t}$ is 0.531 ( $p$-value < 0.0001 ), confirming that efficiency changes based on frontier analysis provide information that is incremental to changes in asset turnover and other variables known to predict future profitability changes. Several fundamental signals such as $I N V_{t}, C A P E X_{t}, G M A R$ $G_{1}, S G A_{t}, E F F T A X_{t}$, and $O P I N I O N_{t}$ show significant and negative coefficients as 
predicted (Lev and Thiagarajan 1993). On the other hand, the positive coefficient on $A R_{t}$ suggests that increases in account receivables convey good news in that management expands credit to increase sales and earnings (Abarbanell and Bushee 1997). While the positive coefficient on $\mathrm{LIFO}_{t}$ is inconsistent with the prediction, it agrees with our results in Table 4 that the use of FIFO is associated with higher profitability. In column 3, we use $M A L M \_S F A_{t}$ to execute our tests and find results similar to those using MALM_DEA $A_{t}$.

We next assess the economic significance of these results by standardizing the coefficients as described above. The coefficient on standardized MALM_DEAt MALM_SFA $A_{t}$ is 0.057 (0.045) (untabulated), which is statistically and economically important. For example, a one standard deviation change in $M A L M_{-} D E A_{t}$ is associated with a 5.7 percent change in current returns. Additionally, the coefficient on standardized MALM_DEA compares favorably to the coefficient on standardized $\triangle A T O_{t}(0.010)$.

Overall, we find that $M A L M_{-} D E A_{t}$ and $M A L M_{-} S F A_{t}$ are positively associated with current returns, consistent with the notion that equity investors impound into current returns the predictive information in frontier-based efficiency changes about current and future profitability changes documented in Tables 4 and 5.

To test whether stock prices fully incorporate the predictive information in efficiency changes (Hypothesis 2B), we regress one-year-ahead returns $\left(R E T_{t+1}\right)$ on MALM_DEA and MALM_SFA $A_{t}$, and control variables used in Table 7. In column 1 of Table 8, we regress future returns on $\triangle A T O_{t}$ and controls. Similar to findings in Soliman 2008, the coefficient on $\triangle A T O_{t}$ is positive and significant, while other variables such as $\triangle R N O A_{t}$, $\triangle P M_{t}$, and $P M_{t}$ are insignificant, suggesting that changes in asset turnover are important for predicting future returns. In column 2, we report that the coefficient on MALM_DEA $A_{t}$ is positive and significant. We find that the coefficients on $I N V_{t}, A R_{t}$, and $O P I N I O N_{t}$ are significantly negative. The positive coefficient on $C A P E X_{t}$ agrees with results in Table 5 and with findings in Abarbanell and Bushee 1998. In column 3, we use MALM_SFA $A_{t}$ and find results similar to those using $M A L M_{-} D E A_{t}$.

To assess the economic significance of results in Table 8 , we again standardize the independent variables. We find (untabulated) that the coefficient on standardized MALM_DEA $\left(M A L M \_S F A_{t}\right)$ is $0.008(0.010)$, which is statistically and economically important in that a one standard deviation change in standardized $M A L M \_D E A_{t}$ is associated with a 0.8 percent increase in future returns. We also find that these coefficients compare favorably with the coefficient on standardized $\triangle A T O_{t}\left(0.006\right.$ with $M A L M_{-} D E A_{t}$ and 0.007 with $M A L$ $M \_S F A_{t}$ ), thus confirming the incremental importance of our frontier-based efficiency measures. Taken together, the evidence in Tables 7 and 8 suggests that equity investors do not fully recognize the implications of frontier-based efficiency changes for profitability changes.

We next assess the magnitude of the abnormal returns associated with this finding. To do so, we form quintile portfolios based on our efficiency measures and other efficiency measures by year, and calculate the time-series means of characteristic-adjusted one-yearahead returns (untabulated). Interestingly, while there are generally significant negative returns in the lowest quintile (Q1) across each measure, there are no clear patterns in the upper quintiles (Q4 and Q5). Upon further examination, we find that firms in Q1 tend to be small and low-priced. ${ }^{27}$ The mean return to a portfolio taking a long position in Q5 and a short position in $\mathrm{Q} 1$ is 3.8 percent for $M A L M_{-} D E A_{t}, 4.0$ percent for $M A L M_{-} S F A_{t}$, and 2.7 percent for $\triangle A T O_{t}$, suggesting that our frontier-based measures compare favorably to simple financial ratios. 28

27. The strong low quintile effect and characteristics of the firms in this group agree with the view that return predictability could be due to market frictions, such as constraints to short-sell and transaction costs.

28. The results are similar when we form tercile, quartile, or decile portfolios or when we use market-adjusted or size-adjusted returns (untabulated). 
TABLE 8

Regressions of future returns on efficiency changes

\begin{tabular}{|c|c|c|c|}
\hline & \multicolumn{3}{|c|}{ Dependent variable $=R E T_{t+1}$} \\
\hline & (1) & $\begin{array}{c}\text { MALM_DEA } \\
\text { (2) }\end{array}$ & $\underset{\text { (3) }}{M A L M \_S F A_{t}}$ \\
\hline Intercept & $-0.055^{* * *}(0.01)$ & $-0.124 * * *(0.00)$ & $-0.201 * * *(0.00)$ \\
\hline$M A L M_{t}$ & & $0.070^{* *}(0.05)$ & $0.146^{* *}(0.02)$ \\
\hline$\triangle R N O A_{t}$ & $0.002(0.87)$ & $-0.001(0.92)$ & $-0.003(0.81)$ \\
\hline$\Delta P M_{t}$ & $0.024(0.26)$ & $0.003(0.90)$ & $-0.002(0.95)$ \\
\hline$\triangle A T O_{t}$ & $0.004 * * *(0.00)$ & $0.003 * * *(0.00)$ & $0.004^{* * *}(0.00)$ \\
\hline$R N O A_{t}$ & $0.025^{* * *}(0.01)$ & $0.024 * *(0.01)$ & $0.024 * * *(0.01)$ \\
\hline$P M_{t}$ & $0.040(0.20)$ & $0.046(0.19)$ & $0.043(0.20)$ \\
\hline$A T O_{t}$ & $0.004 * * *(0.01)$ & $0.004 * * *(0.01)$ & $0.004^{* * *}(0.01)$ \\
\hline$I N V_{t}$ & $-0.014 * * *(0.00)$ & $-0.014 * * *(0.00)$ & $-0.014 * * *(0.00)$ \\
\hline$A R_{t}$ & $-0.014 * * *(0.01)$ & $-0.014 * * *(0.01)$ & $-0.014 * * *(0.01)$ \\
\hline$C A P E X_{t}$ & $0.013^{* * *}(<.0001)$ & $0.013 * * *(<.0001)$ & $0.013^{* * *}(<.0001)$ \\
\hline GMARGIN $_{t}$ & $-0.007(0.50)$ & $-0.003(0.74)$ & $-0.002(0.86)$ \\
\hline$S G A_{t}$ & $-0.005(0.67)$ & $0.004(0.72)$ & $0.003(0.79)$ \\
\hline EFFTAX $X_{t}$ & $0.013(0.81)$ & $0.013(0.81)$ & $0.012(0.83)$ \\
\hline$L^{\prime} \mathrm{OO}_{t}$ & $-0.011(0.14)$ & $-0.011(0.13)$ & $-0.011(0.14)$ \\
\hline OPINION $_{t}$ & $-0.022 * *(0.03)$ & $-0.023 * *(0.03)$ & $-0.022 * *(0.03)$ \\
\hline$L A B O R_{t}$ & $0.016 *(0.10)$ & $0.018 *(0.05)$ & $0.018 *(0.07)$ \\
\hline Industry indicators & Yes & Yes & Yes \\
\hline Average adj. $R^{2}$ & $5.16 \%$ & $5.19 \%$ & $5.20 \%$ \\
\hline
\end{tabular}

Notes:

This table reports the time-series cross-sectional regression estimates of one-year-ahead characteristic-adjusted stock returns on frontier-based efficiency changes and controls. The $p$-values in parentheses are based on Fama-MacBeth 1973 standard errors with the NeweyWest 1987 adjustment. The dependent variable $\left(R E T_{t+1}\right)$ is computed by taking the 12-month buy-and-hold return and subtracting the stock's corresponding benchmark portfolio return according to firm size, book-to-market ratio, and momentum. The return cumulation period begins 3 months after the fiscal year-end. $M A L M_{t}$ in column 2 is the Malmquist index estimated from DEA, and $M A L M_{t}$ in column 3 is the Malmquist index estimated from SFA. See Appendix 3 for the definitions of the other variables. The sample is 71,733 observations for the period 1976-2008. All tests are two-tailed. The symbols *,**, and *** denote significance at the $0.1,0.05$, and 0.01 levels, respectively.

\section{Do analysts impound the information in efficiency changes?}

We next test whether analysts impound into their forecast revisions the information in efficiency changes about future profitability changes (Hypothesis 3A). We present results in the first two columns of Table 9. If analysts impound information from efficiency changes in their forecasts revisions, then we expect similar patterns to those observed in Table 5 for the relation between efficiency changes and future profitability changes. In the regressions of one-year-ahead forecast revisions $\left(R E V_{t+1}\right)$, we find a significant and positive coefficient on both $M A L M_{-} D E A_{t}$ and $M A L M_{-} S F A_{t}$, suggesting that analysts understand the systematic relation between efficiency changes and future profitability changes. We also report a positive but insignificant coefficient on $\triangle A T O_{t}$. Taken together, results for the forecast revision tests suggest that the predictive information in frontier-based measures is incremental to the predictive information in simple financial ratios. 
TABLE 9

Regressions of analysts' forecast revisions and forecast errors on efficiency changes

Sample period: 1990-2008

$\frac{\text { Dependent variable }=R E V_{t+1}}{M A L M D E A_{t}} \quad \begin{gathered}\text { Dependent variable }=F E_{t+1} \\ \text { MALM SFA }\end{gathered}$

(1)

(2)

(3)

(4)

\begin{tabular}{|c|c|c|c|c|}
\hline Intercept & $-0.004 *(0.06)$ & $-0.009 * *(0.03)$ & $-0.014 *(0.07)$ & $-0.019(0.23)$ \\
\hline$>M A L M_{t}$ & $0.004 *(0.06)$ & $0.009 * *(0.03)$ & $0.010(0.20)$ & $0.015(0.35)$ \\
\hline$F E_{t}$ & $0.127 * * *(<.0001)$ & $0.126^{* * *}(<.0001)$ & $0.276^{* * *}(0.00)$ & $0.277 * * *(0.00)$ \\
\hline$\triangle R N O A_{t}$ & $0.001 * * *(0.01)$ & $0.001 * * *(0.00)$ & $-0.002(0.36)$ & $-0.002(0.25)$ \\
\hline$\Delta P M_{t}$ & $0.002(0.28)$ & $0.001(0.62)$ & $-0.005(0.23)$ & $-0.004(0.31)$ \\
\hline$\triangle A T O_{t}$ & $0.000(0.18)$ & $0.000(0.10)$ & $0.000(0.47)$ & $0.000(0.32)$ \\
\hline$P M_{t}$ & & & $0.005^{* *}(0.03)$ & $0.005 * *(0.03)$ \\
\hline$A T O_{t}$ & & & $0.000 * * *(0.00)$ & $0.000 * * *(0.00)$ \\
\hline$I N V_{t}$ & $0.000(0.47)$ & $0.000(0.46)$ & $-0.001(0.13)$ & $-0.001(0.13)$ \\
\hline$A R_{t}$ & $0.000 *(0.08)$ & $0.000 * *(0.04)$ & $0.000(0.79)$ & $0.000(0.74)$ \\
\hline$C A P E X_{t}$ & $0.000(0.65)$ & $0.000(0.66)$ & $0.000(0.51)$ & $0.000(0.43)$ \\
\hline GMARGIN $_{t}$ & $0.000(0.52)$ & $0.000(0.62)$ & $-0.003(0.14)$ & $-0.003(0.19)$ \\
\hline$S G A_{t}$ & $0.001(0.52)$ & $0.001(0.48)$ & $-0.002(0.42)$ & $-0.003(0.19)$ \\
\hline EFFTAX ${ }_{t}$ & $0.003(0.23)$ & $0.003(0.28)$ & $0.030 * *(0.03)$ & $0.029 * *(0.03)$ \\
\hline$L I F O_{t}$ & $-0.001(0.10)$ & $-0.001(0.10)$ & $-0.001 * *(0.05)$ & $-0.001 *(0.05)$ \\
\hline OPINION $_{t}$ & $0.000(0.37)$ & $0.000(0.36)$ & $0.000(0.67)$ & $0.000(0.68)$ \\
\hline$L A B O R_{t}$ & $0.000(0.84)$ & $0.000(0.91)$ & $0.001(0.49)$ & $0.001(0.57)$ \\
\hline $\begin{array}{l}\text { Industry } \\
\text { indicators }\end{array}$ & Yes & Yes & Yes & Yes \\
\hline Average adj. $R^{2}$ & $9.92 \%$ & $9.95 \%$ & $8.12 \%$ & $8.18 \%$ \\
\hline
\end{tabular}

Notes:

This table reports the time-series cross-sectional regression estimates of analysts' one-year-ahead forecast revisions and errors on frontier-based efficiency changes and controls. The $p$-values in parentheses are based on Fama-MacBeth 1973 standard errors with the Newey-West 1987 adjustment. The dependent variable in columns 1 and $2\left(R E V_{t+1}\right)$ is the analyst revision of the one-year-ahead earnings forecast, measured as the revision to the consensus analyst forecast of year $t+1$ earnings made just after year $t$ earnings are announced. The dependent variable in columns 3 and $4\left(F E_{t+1}\right)$ is the realized earnings for year $t+1$ less the median earnings forecast from the month prior to the announcement of $t+1$ earnings, scaled by the stock price at the end of the month of the earnings announcement for year $t$. See Appendix 3 for the definitions of the other variables. The sample is 24,811 observations for the period 1990-2008. All tests are two-tailed. The symbols *,**, and *** denote significance at the $0.1,0.05$, and 0.01 levels, respectively.

To assess whether analysts fully impound the information in efficiency changes about future profitability changes (Hypothesis 3B), we examine the relation between our efficiency measures and future forecast errors $\left(F E_{t+1}\right)$. The last two regressions in Table 9 show that neither the coefficient on $M A L M_{-} D E A_{t}$ nor the coefficient on MALM_SFA $A_{t}$ is significant, suggesting that analysts fully incorporate the information in efficiency changes about future profitability changes.

Overall, results from this subsection suggest that analysts have a deep understanding of firms' efficiency, which is in contrast to results for future returns. However, these seemingly contradictory results are consistent with prior research, which suggests that equity 
investors and analysts respond differently to accounting information, perhaps due to market frictions such as short-sale constraints or transaction costs (see, e.g., Rajgopal et al. 2003).

\section{Robustness tests}

For robustness, we conduct the following series of untabulated tests.

- To assess the possibility that a systematic relation between our efficiency measures and firm size drives our results, we divide the sample into two groups based on total assets and repeat the regressions for current and one-year-ahead profitability changes. For all subsamples sorted by firm size, the coefficients on both $M A L M_{-} D E A_{t}$ and $M A L M \_S F A_{t}$ are positive and significant, suggesting that firm size does not drive our results.

- To control for the possibility that market prices drive our results for future profitability changes, we follow Weiss, Naik, and Tsai 2008 and reestimate the changes in future profitability regressions after including market-adapted earnings as an additional control variable. We obtain results similar to those reported.

- We follow Demerjian et al. 2012 and add to our original three input variables the following four input variables to estimate the DEA-based Malmquist index: (i) capitalized operating leases, (ii) capitalized research and development (R\&D) costs, (iii) purchased goodwill, and (iv) other intangibles. We find that the coefficients on MALM_DEA $t$ and MALM_SFA $A_{t}^{29}$ are positive and significant in all specifications, similar to results reported earlier in the paper.

- It is possible that changes in technology rather than by changes in technical efficiency drive our main results. However, after splitting our measures of efficiency changes into their technical efficiency and technology components, we find that our results are generally driven by technical efficiency changes.

- We also estimate pooled regressions using standard errors clustered by firm or by both firm and year (Petersen 2009), repeat our analyses without conditioning on the nine fundamental signals, reestimate our future returns regressions using accruals from Richardson et al. 2005, and replace changes in asset turnover with its components of changes in accounts receivable turnover, changes in inventory turnover, and changes in PPE turnover (Penman 2007). Results from these tests do not change the tenor of reported results.

\section{Summary and conclusions}

In this paper, we provide large-sample evidence on the association between efficiency changes estimated from frontier analysis and firm performance. While DEA and SFA have been widely used in management accounting, there is scant empirical evidence on the use of frontier analysis for predicting changes in future firm performance. Our study seeks to fill this void.

Using a large sample of observations for the years 1976-2008, we provide robust evidence that efficiency change measures based on frontier analysis are positively associated with current and future profitability changes, even after controlling for fundamental signals (Abarbanell and Bushee 1997) and changes in asset turnover (Fairfield and Yohn 2001; Soliman 2008). These findings suggest that firms which improve efficiency exhibit higher profitability changes in the current and future years. We also show that efficiency changes are positively related to contemporaneous and future returns. The latter finding implies that equity investors do not fully incorporate the information in efficiency changes.

29. Because the translog production function used in SFA is not defined for missing or zero input values, we estimate MALM_SFAt by substituting $\$ 1$ for all missing observations for the additional variables. 
In contrast to the findings for equity investors, we find evidence suggesting that analysts fully impound in their forecasts the information in efficiency changes about future profitability changes. Overall, our evidence highlights that measures derived from frontier-based efficiency changes improve profitability forecasts. This evidence should be useful for investment decisions.

\section{Appendix 1}

\section{Data Envelope Analysis (DEA)-based Malmquist index}

DEA is a nonparametric method that uses multiple inputs and outputs to measure the relative efficiency of decision-making units (DMUs). DEA creates a best-practice or efficient frontier of observed production points from linear programming to maximize a ratio of outputs to inputs. DMUs located at the frontier are those with maximum output levels given input levels or with minimum input levels given output levels, while DMUs below the frontier are inefficient units. DEA assigns a value of one to the frontier (efficient) DMUs and a value of less than one to inefficient DMUs. The efficiency score for inefficient units can be interpreted as the distance from the frontier (see Cooper, Seiford, and Tone 2000 for more information). In addition, the DEA calculation is independent of the units of measurement used.

To measure efficiency changes over time, we employ the Malmquist index, which was first introduced by Malmquist in 1953 and further developed by Caves, Christensen, and Diewert in 1982. We use the DEA-based Malmquist index $\left(M A L M_{-} D E A_{t}\right)$, following Färe et al. 1992, 1994, which is the geometric mean of two Malmquist indexes of Caves et al. 1982. The calculation of MALM_DEA proceeds as follows. Suppose we have a production function at time $t$ and $t+\overline{1}$. The Malmquist index calculation requires two single period (e.g., input and output of period $t$ with the production function of period $t$ ) and two mixed-period measures (e.g., input and output of period $t$ with the production function of period $t+1$ ). The efficiency score in period $t$ can be expressed as follows (Charnes, Cooper, and Rhodes 1978):

$\mathrm{D}_{\mathrm{o}}^{\mathrm{t}}\left(\mathrm{x}_{\mathrm{o}}^{\mathrm{t}}, \mathrm{y}_{\mathrm{o}}^{\mathrm{t}}\right)=\min \theta$

s.t.

$\sum_{j=1}^{n} \lambda_{j} x_{i j}^{t} \leq \theta x_{i o}^{t}, i=1,2, \ldots m$,

$\sum_{j=1}^{n} \lambda_{j} y_{r j}^{t} \geq y_{r o}^{t}, r=1,2, \ldots s$

$\lambda_{\mathrm{j}} \geq 0, \mathrm{j}=1,2, \ldots, \mathrm{n}$

where $\mathrm{x}_{\mathrm{io}}^{\mathrm{t}}$ is the $i$ th input and $\mathrm{y}_{\mathrm{ro}}^{\mathrm{t}}$ is the $r$ th output for $\mathrm{DMU}_{\mathrm{o}}$ in time period $t$. The efficiency $\mathrm{D}_{\mathrm{o}}^{\mathrm{t}}\left(\mathrm{x}_{\mathrm{o}}^{\mathrm{t}}, \mathrm{y}_{\mathrm{o}}^{\mathrm{t}}\right)=\theta^{*}$ determines the amount by which observed inputs can be reduced while still producing the given output level. Using $t+1$ instead of $t$ allows us to obtain the efficiency score in period $t+1$.

Färe et al.'s 1992 input-oriented Malmquist index, which measures the efficiency change of a $\mathrm{DMU}_{\mathrm{o}}, \mathrm{o} \in \mathrm{Q}=\{1,2, \ldots, \mathrm{n}\}$ in time $t$ and $t+1$, is given as follows (Chen and Ali 2004):

Malmquist Index $=$ MALM $_{\mathrm{o}}=\left[\frac{\mathrm{D}_{\mathrm{o}}^{\mathrm{t}}\left(\mathrm{y}^{\mathrm{t}+1}, \mathrm{x}^{\mathrm{t}+1}\right)}{\mathrm{D}_{\mathrm{o}}^{\mathrm{t}}\left(\mathrm{y}^{\mathrm{t}}, \mathrm{x}^{\mathrm{t}}\right)} \frac{\mathrm{D}_{\mathrm{o}}^{\mathrm{t}+1}\left(\mathrm{y}^{\mathrm{t}+1}, \mathrm{x}^{\mathrm{t}+1}\right)}{\mathrm{D}_{\mathrm{o}}^{\mathrm{t}+1}\left(\mathrm{y}^{\mathrm{t}}, \mathrm{x}^{\mathrm{t}}\right)}\right]^{\frac{1}{2}}$ 
MALM $_{\mathrm{O}}>1$ indicates an efficiency gain, $\mathrm{MALM}_{\mathrm{O}}<1$ indicates an efficiency loss, and $\mathrm{MALM}_{\mathrm{O}}=1$ means no efficiency change, all measured from time $t$ to $t+1$.

The Malmquist index can be further decomposed into two components, one measuring changes in technical efficiency and the other measuring changes in frontier technology.

Malmquist Index $=M_{o}=\frac{D_{o}^{t+1}\left(y^{t+1}, x^{t+1}\right)}{D_{o}^{t}\left(y^{t}, x^{t}\right)}\left[\frac{D_{o}^{t}\left(y^{t+1}, x^{t+1}\right)}{D_{o}^{t+1}\left(y^{t+1}, x^{t+1}\right)} \frac{D_{o}^{t}\left(y^{t}, x^{t}\right)}{D_{o}^{t+1}\left(y^{t}, x^{t}\right)}\right]^{\frac{1}{2}}$

The first component measures changes in technical efficiency, which represents the degree to which a DMU improves or worsens its efficiency (i.e., the distance from the frontier). The second component measures changes in the frontier technology (i.e., innovation), which involves improvement or decline in technology.

Nonparametric approaches such as DEA have the benefit of not assuming a particular functional form of the relation between inputs and outputs in an arbitrary manner. More importantly, DEA avoids a need for a priori choices of factor weights because optimal weights are derived from the data (Cooper et al. 2000).

Although DEA has proponents, there is substantial debate about the merits of the DEA technique. Some have questioned the ability of DEA to derive efficiencies by a mechanical technique without value judgments on different outputs or outcomes. For example, Stone (2002) proposes the use of externally determined fixed weights with reference to context. Stone (2002) also criticizes DEA as being too simplistic because of its inability to handle more than a few outputs (please see Cooper and Ray 2008 for counterarguments).

\section{Appendix 2}

\section{Stochastic Frontier Analysis (SFA)-based Malmquist index}

SFA, first suggested by Aigner, Lovell, and Schmidt 1977 and Meeusen and Van Den Broeck 1977, is a commonly used method to evaluate the relative efficiency of a firm (Lovell 1996; Cummins and Zi 1998; Dopuch et al. 2003; Casu, Girardone, and Molyneux 2004). SFA measures efficiency relative to a stochastic parametric frontier. SFA assumes that the deviation of each unit from the efficient frontier results from two sources: (a) a symmetric random noise component and (b) a one-sided inefficiency component. The general SFA model can be expressed as follows:

$\mathrm{q}_{\mathrm{i}}=\mathrm{x}_{\mathrm{i}} \beta+\left(\mathrm{v}_{\mathrm{i}}-\mathrm{u}_{\mathrm{i}}\right), \mathrm{I}=1, \ldots, \mathrm{I}$

where $q_{i}$ is the production (or the logarithm of the production) of the $i$ th firm; $x_{i}$ is a $\mathrm{k}^{*} 1$ vector of (or the transformation of the) input of the $i$ th firm; the $v_{i}$ s are random errors, assumed to be i.i.d and have $\mathrm{N}\left(0, \sigma_{v}^{2}\right)$ distribution, independent of the $u_{i}$; and the $u_{i} \mathrm{~s}$ are non-negative random variables that are assumed to account for technical inefficiency in production.

SFA also assumes that the error term consists of two components, one to account for random effects $\left(v_{i}\right)$ and another one to account for technical inefficiency $\left(u_{i}\right)$. There are many different SFA models that can be used to measure efficiency changes (Bauer 1990; Lovell 1996; Kim and Han 2001). Given that we focus our research questions on how changes in efficiency impact changes in firm performance, we use the Malmquist efficiency index calculation applied to SFA (Coelli et al. 2005). 
We use a translog stochastic production frontier for a panel, defined as follows:

$$
\begin{aligned}
\ln \mathrm{q}_{\mathrm{it}}= & \beta_{0}+\sum_{\mathrm{n}=1}^{\mathrm{N}} \beta_{\mathrm{n}} \ln \mathrm{x}_{\mathrm{nit}}+\frac{1}{2} \sum_{\mathrm{n}=1}^{\mathrm{N}} \sum_{\mathrm{j}=1}^{\mathrm{N}} \beta_{\mathrm{nj}} \ln \mathrm{x}_{\mathrm{nit}} \ln \mathrm{x}_{\mathrm{nit}}+\sum_{\mathrm{j}=1}^{\mathrm{N}} \beta_{\mathrm{tn}} \mathrm{t} \ln \mathrm{x}_{\mathrm{nit}}+\beta_{\mathrm{t}} \mathrm{t} \\
& +\frac{1}{2} \beta_{\mathrm{tt}} \mathrm{t}^{2}+\mathrm{v}_{\mathrm{it}}-\mathrm{u}_{\mathrm{it}} \\
\mathrm{I} & =1,2, \ldots, \mathrm{I}, t=1,2, \ldots T .
\end{aligned}
$$

where $q_{i t}$ is the output of the $i$ th firm in the $t$ th year; $X_{n i t}$ denotes an $n$th input variable; $T$ is a time trend representing technical change; the $\beta$ s are unknown parameters to be estimated; the $v_{i t} \mathrm{~s}$ are random errors, assumed to be i.i.d and have $\mathrm{N}\left(0, \sigma_{v}^{2}\right)$ distribution, independent of the $u_{i t} \mathrm{~s}$; and the $u_{i t} \mathrm{~s}$ are non-negative random variables, assumed to be i.i.d. $\mathrm{N}^{+}\left(0, \sigma_{u}^{2}\right)$.

Once parameters are estimated, we obtain the technical efficiency measure for each firm in each year $\left(T E_{i t}\right)$ by calculating the conditional expectation of $\exp \left(-u_{i t}\right)$, given the value of $e_{i t}=v_{i t}-u_{i t}$ (i.e., technical efficiency $\left.=E\left(\exp \left(-u_{i t}\right) \mid e_{i t}\right)\right)$. Changes in technical efficiency, which implies moving towards the frontier, can be expressed as the ratio of the current period's efficiency to the previous period's efficiency.

Technical efficiency change $=T E_{i t} / T E_{i t-1}$

The second component of the Malmquist index, changes in technology, reflects shifts in the frontier or innovation between the periods. The technology change index between $t$ and $t-1$ is calculated as the geometric mean of two partial derivatives of the production function with respect to time $(t)$, which is equivalent to the exponential of the arithmetic mean of the log derivatives when a translog function is used.

Technology change $=\exp \left\{\frac{1}{2}\left[\frac{\partial \ln q_{i t-1}}{\partial_{t-1}}+\frac{\partial \ln q_{i t}}{\partial_{t}}\right]\right\}$

The product of the technical efficiency change index and technology change index yields the Malmquist Total Factor Productivity index $\left(M A L M \_S F A_{t}\right)$. We present the estimates of the parameters of equation (B2) at the end of this appendix in Table A1.

SFA differs from DEA in that SFA allows for random variation in the production process, while DEA does not allow DMUs to deviate from the frontier due to pure random shocks. Although SFA is innovative in separating random shocks from technical efficiency, the delicacy and lack of robustness to assumptions of any method of doing this may pose a significant challenge to reality (Stone 2002). In addition, unlike DEA, a functional form for the relation between inputs and outputs and distributional assumption on $u_{i}$ needs to be specified for SFA, which has been criticized as being arbitrary.

TABLE A1

Maximum-likelihood estimates of the Stochastic Frontier (SFA) model

\begin{tabular}{lrrrrr}
\hline Coefficient & Estimate & $t$-Value & Coefficient & Estimate & $t$-Value \\
\hline$\beta_{0}$ & $0.184^{* * *}$ & $(9.59)$ & $\beta_{22}$ & $0.100^{* * *}$ & $(7.86)$ \\
$\beta_{1}$ & $0.683^{* * *}$ & $(32.03)$ & $\beta_{23}$ & 0.004 & $(0.42)$ \\
$\beta_{2}$ & $0.278^{* * *}$ & $(13.59)$ & $\beta_{2 t}$ & $-0.001^{*}$ & $(-1.97)$
\end{tabular}

(The table is continued on the next page.) 
TABLE A1 (Continued)

\begin{tabular}{lrrllr}
\hline Coefficient & Estimate & $t$-Value & Coefficient & Estimate & $t$-Value \\
\hline$\beta_{3}$ & $0.061^{* * *}$ & $(7.75)$ & $\beta_{33}$ & $0.030^{* * *}$ & $(4.15)$ \\
$\beta_{t}$ & -0.001 & $(-0.97)$ & $\beta_{3 t}$ & 0.000 & $(-0.21)$ \\
$\beta_{11}$ & $0.100^{* * *}$ & $(11.43)$ & $\beta_{t t}$ & $0.000^{*}$ & $(1.71)$ \\
$\beta_{12}$ & $-0.091^{* * *}$ & $(-12.17)$ & $\sigma^{2}$ & $0.161^{* * *}$ & $(5.45)$ \\
$\beta_{13}$ & $-0.032^{* * *}$ & $(-6.73)$ & $\gamma$ & $0.813^{* * *}$ & $(30.17)$ \\
$\beta_{1 t}$ & $0.003^{* *}$ & $(2.48)$ & & & \\
\hline
\end{tabular}

\section{Notes:}

This table reports the mean value of maximum-likelihood estimates of the parameters of the translog stochastic frontier model in (B2). $\mathrm{X}_{1}$ is cost of goods sold, $\mathrm{X}_{2}$ is selling, general and administrative expense, and $\mathrm{X}_{3}$ is net property, plant, and equipment. The equation (B2) is estimated separately for 42 Fama-French industries, and the mean value of coefficients are reported in the table. The $t$-values in parentheses are based on the distribution of estimated coefficients.

\section{Appendix 3}

\section{Definitions of variables}

\begin{tabular}{|c|c|}
\hline Variable & Definition \\
\hline$I N V_{t}$ & $\begin{array}{l}\text { Annual percentage change in inventory minus annual percentage change in } \\
\text { sales, } \Delta \text { Inventory (INVFG or INVT) }-\Delta \text { Sales (SALE) }\end{array}$ \\
\hline$A R_{t}$ & $\begin{array}{l}\text { Annual percentage change in accounts receivable minus annual percentage } \\
\text { change in sales, } \Delta \text { Accounts receivable (RECT) }-\Delta \text { Sales (SALE) }\end{array}$ \\
\hline$C A P E X_{t}$ & $\begin{array}{l}\text { Annual percentage change in industry capital expenditures minus annual } \\
\text { percentage change in firm capital expenditures, } \Delta \text { Industry capital expenditures } \\
-\Delta \text { Firm capital expenditures (CAPXV) }\end{array}$ \\
\hline$G M A R G I N_{t}$ & $\begin{array}{l}\text { Annual percentage change in sales minus annual percentage change in gross } \\
\text { margin, } \Delta \text { Sales (SALE) }-\Delta \text { Gross margin (= SALE - COGS) }\end{array}$ \\
\hline$S G A_{t}$ & $\begin{array}{l}\text { Annual percentage change in selling, general, and administrative expenses minus } \\
\text { annual percentage change in sales, } \Delta \text { S\&A (XSGA) }-\Delta \text { Sales (SALE) }\end{array}$ \\
\hline EFFTA $X_{t}$ & Changes in effective tax rate $\left[\left(\frac{1}{3} \sum_{\tau=1}^{3} E T R_{t-\tau}\right)-E T R_{t}\right] \times$ Current earnings change \\
\hline & where $E T R_{t}=\frac{\text { Tax Expense }(T X T)_{t}}{E B T(=P I+A M)_{t}}$ \\
\hline$L I F O_{t}$ & $\begin{array}{l}\text { An indicator for inventory method, } 0 \text { for LIFO and replacement cost, } 1 \text { for } \\
\text { FIFO or other (INVVAL) }\end{array}$ \\
\hline$O P I N I O N_{t}$ & $\begin{array}{l}\text { An indicator for qualified, disclaimed, or adverse audit opinions, } 0 \text { for unqualified } \\
\text { opinion, } 1 \text { for qualified or other (AUOP) }\end{array}$ \\
\hline \multirow[t]{2}{*}{$L A B O R_{t}$} & Annual percentage change in sales-per-employee (the ratio of annual sales to the \\
\hline & number of employees at year-end), $\left[\frac{\text { Sales }_{t-1}}{i \text { Employees }_{t-1}}-\frac{\text { Sales }_{t}}{\# \text { Employees }_{t}}\right] / \frac{\text { Sales }_{t-1}}{i{\text { Employees }(\text { EMP })_{t-1}}}$ \\
\hline$\triangle P P E T O_{t}$ & Changes in PP\&E turnover, Sales $_{t} /$ Net $P P \& E_{t-1}$ \\
\hline$\Delta E M P_{-} P_{t}$ & Changes in employee productivity, Sales $/$ /\# Employees Em-1 \\
\hline
\end{tabular}

(The table is continued on the next page.) 
Appendix 3 (Continued)

\begin{tabular}{|c|c|}
\hline Variable & Definition \\
\hline$M A L M_{-} D E A_{t}$ & $\begin{array}{l}\text { The Malmquist index based on Data Envelopment Analysis (DEA) using } \\
\text { three inputs and one output } \\
\text { - Inputs: net PP\&E (PPENT) at the beginning of the fiscal year, } \\
\text { cost of goods sold (COGS), and selling, general, and administrative } \\
\text { expenses (XSGA). } \\
\text { - Output: revenues (SALE) }\end{array}$ \\
\hline$M A L M \_S F A_{t}$ & $\begin{array}{l}\text { The Malmquist index estimated from Stochastic Frontier Analysis (SFA). } \\
\text { Input and output variables are the same as those used in } M A L M_{-} D E A_{t} \\
\text { estimation. }\end{array}$ \\
\hline$E F F C H \_D E A_{t}$ & Technical efficiency changes estimated from DEA as described in Appendix 1 \\
\hline$T E C C H_{-} D E A_{t}$ & Technology changes estimated from DEA as described in Appendix 1 \\
\hline$E F F C H \_S F A_{t}$ & Technical efficiency changes estimated from SFA as described in Appendix 2 \\
\hline TECCH_SFA $A_{t}$ & Technology changes estimated from SFA as described in Appendix 2 \\
\hline$R E T_{t}$ & $\begin{array}{l}\text { 12-month buy-and-hold return, minus the stock's corresponding benchmark } \\
\text { portfolio return based on firm size, book-to-market, and momentum. } \\
\text { The return cumulation begins } 3 \text { months after the beginning of the fiscal year. }\end{array}$ \\
\hline$R E T_{t+1}$ & $\begin{array}{l}\text { 12-month buy-and-hold return, minus the stock's corresponding benchmark } \\
\text { portfolio return. The return cumulation begins } 3 \text { months after the fiscal year-end. }\end{array}$ \\
\hline$R N O A_{t}$ & 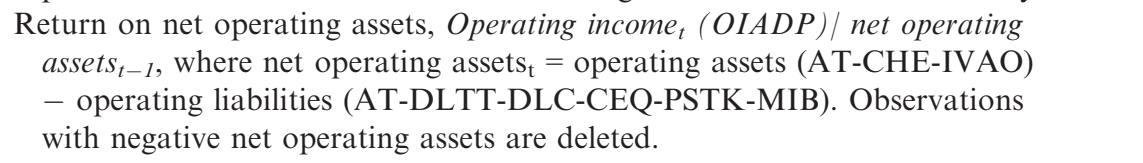 \\
\hline$\triangle R N O A_{t}$ & Change in return on net operating assets, $R N O A_{t}-R N O A_{t-1}$ \\
\hline$A T O_{t}$ & Asset turnover, Sales ${ }_{t} /$ Net operating assets $_{t-1}$ \\
\hline$\triangle A T O_{t}$ & Changes in asset turnover, $A T O_{t}-A T O_{t-1}$ \\
\hline$P M_{t}$ & Profit margin, Operating income $_{t} /$ Sales $_{t}$ \\
\hline$\Delta P M_{t}$ & Change in profit margin, $P M_{t}-P M_{t-1}$ \\
\hline$E A R N_{t}$ & $\begin{array}{l}\text { Earnings per share, divided by stock price at the beginning of the year, } \\
\qquad \operatorname{EPS}_{t}(\operatorname{EPSPX}) / P_{t-1}\end{array}$ \\
\hline$\triangle E A R N_{t}$ & $\begin{array}{l}\text { Changes in earnings per share, divided by stock price at the beginning of the } \\
\text { year, } \triangle E P S_{t}(E P S P X) / P_{t-1}\end{array}$ \\
\hline$R E V_{t+1}$ & $\begin{array}{l}\text { The first } \mathrm{I} / \mathrm{B} / \mathrm{E} / \mathrm{S} \text { consensus (median) forecast of year } t+1 \text { earnings minus } \\
\text { the last consensus of year } t+1 \text { earnings made directly before the announcement } \\
\text { of year } t \text { earnings, scaled by the stock price at the end of fiscal year } t-1\end{array}$ \\
\hline$F E_{t+1}$ & $\begin{array}{l}\text { The realized earnings for year } t+1 \text { less the } \mathrm{I} / \mathrm{B} / \mathrm{E} / \mathrm{S} \text { median earnings forecast } \\
\text { from the month prior to the announcement of } t+1 \text { earnings, scaled by the } \\
\text { stock price at the end of the month of the earnings announcement for year } t\end{array}$ \\
\hline
\end{tabular}

Notes:

The definitions of the fundamental signals come from Abarbanell and Bushee 1997. COMPUSTAT $\mathrm{XPF}$ names are presented in parentheses.

\section{References}

Abarbanell, J. S., and V. L. Bernard. 1992. Tests of analysts' overreaction/underreaction to earnings information as an explanation for anomalous stock price behavior. The Journal of Finance 47 (3): 1181-207.

Abarbanell, J. S., and B. L. Bushee. 1997. Fundamental analysis, future earnings, and stock prices. Journal of Accounting Research 35 (1): 1-24. 
Abarbanell, J. S., and R. Lehavy. 2003. Biased forecasts or biased earnings? The role of reported earnings in explaining apparent bias and over/underreaction in analysts' earnings forecasts. Journal of Accounting and Economics 36 (1-3): 105-46.

Aigner, D. J., C. A. K. Lovell, and P. Schmidt. 1977. Formulation and estimation of stochastic frontier production function models. Journal of Econometrics 6 (1): 21-37.

Alam, I. M. S., and R. C. Sickles. 1998. The relationship between stock market returns and technical efficiency innovations: Evidence from the US airline industry. Journal of Productivity Analysis 9 (1): 35-51.

Banker, R. D., and L. Chen. 2006. Predicting earnings using a model based on cost variability and cost stickiness. The Accounting Review 81 (2): 285-307.

Battese, G. E., and T. J. Coelli. 1992. Frontier production functions, technical efficiency and panel data: With application to paddy famers in India. Journal of Productivity Analysis 3 (1-2): 15369.

Battese, G. E., and T. J. Coelli. 1995. A model for technical inefficiency effects in a stochastic frontier production function for panel data. Empirical Economics 20 (2): 325-32.

Bauer, P. W. 1990. Decomposing TFP growth in the presence of cost inefficiency, nonconstant returns to scale, and technological progress. Journal of Productivity Analysis 1 (4): 287-99.

Berger, A. N., and L. J. Mester. 1997. Efficiency and productivity change in the U.S. commercial banking industry: A comparison of the 1980s and 1990s. Working paper, University of Pennsylvania.

Bradshaw, M. T., S. A. Richardson, and R. G. Sloan. 2001. Do analysts and auditors use information in accruals? Journal of Accounting Research 39 (1): 45-74.

Bradshaw, M. T., and R. G. Sloan. 2002. GAAP versus the street: An empirical assessment of two alternative definitions of earnings. Journal of Accounting Research 40 (1): 41-66.

Brown, L., G. D. Richardson, and S. J. Schwager. 1987. An information interpretation of financial analyst superiority in forecasting earnings. Journal of Accounting Research 25 (1): 49-67.

Byard, D., and F. Cebenoyan. 2007. Alternative evidence on financial analysts' use of financial statement information. Review of Accounting and Finance 6 (4): 442-59.

Callen, J. 1991. Data envelopment analysis: Partial survey and applications for management accounting. Journal of Management Accounting Research 3 (1): 35-56.

Callen, J. L., and H. Falk. 1993. Agency and efficiency in nonprofit organizations: The case of "specific health focus" charities. The Accounting Review 68 (1): 48-65.

Callen, J. L., M. Morel, and C. Fader. 2005. Productivity measurement and the relationship between plant performance and JIT intensity. Contemporary Accounting Research 22 (2): 271-309.

Casu, B., C. Girardone, and P. Molyneux. 2004. Productivity change in European banking: A comparison of parametric and non-parametric approaches. Journal of Banking \& Finance 28 (10): 2521-540.

Caves, D., L. Christensen, and E. Diewert. 1982. The economic theory of index numbers and the measurement of input, output, and productivity. Econometrica 50 (6): 1393-414.

Chandra, P., W. W. Cooper, S. Li, and A. Rahman. 1998. Using DEA to evaluate 29 Canadian textile companies: Considering returns to scale. International Journal of Production Economics 54 (2): $129-41$.

Chang, H., H. L. Choy, W. W. Cooper, and T. W. Ruefli. 2009. Using Malmquist indexes to measure changes in the productivity and efficiency of US accounting firms before and after the Sarbanes-Oxley Act. Omega 37 (5): 951-60.

Charnes, A., W. W. Cooper, and E. Rhodes. 1978. Measuring the efficiency of decision making units. European Journal of Operations Research 2 (6): 429-44.

Chen, Y., and A. I. Ali. 2004. DEA Malmquist productivity measure: New insights with an application to computer industry. European Journal of Operational Research 159 (1): 239-49.

Coelli, T. J., D. S. P. Rao, C. J. O'Donnell, and G. E. Battese. 2005. An introduction to efficiency and productivity analysis, 2nd ed. New York: Springer. 
Cooper, W. W., and S. C. Ray. 2008. A response to M. Stone: "How not to measure the efficiency of public services (and how one might)." Journal of the Royal Statistical Society 171 (2): 433-48.

Cooper, W. W., L. M. Seiford, and K. Tone. 2000. Data envelopment analysis: A comprehensive text with models, applications, references and DEA-Solver software. Dordrecht, Netherlands: Kluwer Academic Publishers.

Cummins, J. D., S. Tennyson, and M. A. Weiss. 1999. Consolidation and efficiency in the US life insurance industry. Journal of Banking \& Finance 23 (2): 325-57.

Cummins, J. D., and X. Xie. 2008. Market value relevance of frontier efficiency: Evidence from U.S. property-liability insurer acquisitions and divestitures. Working paper, Temple University.

Cummins, J. D., and H. Zi. 1998. Comparison of frontier efficiency methods: An application to the U.S. life insurance industry. Journal of Productivity Analysis 10 (2): 131-52.

Daniel, K., M. Grinblatt, S. Titman, and R. Wermers. 1997. Measuring mutual fund performance with characteristic based benchmarks. The Journal of Finance 52 (3): 1035-058.

Demerjian, P., B. Lev, and S. McVay. 2012. Quantifying managerial ability: A new measure and validity tests. Management Science 58 (7): 1229-248.

Dopuch, N., and M. Gupta. 1997. Estimation of benchmark performance standards: An application to public school expenditures. Journal of Accounting and Economics 23 (2): 141-61.

Dopuch, N., M. Gupta, D. A. Simunic, and M. T. Stein. 2003. Production efficiency and the pricing of audit services. Contemporary Accounting Research 20 (1): 47-77.

Dybvig, P. H., and M. Warachka. 2010. Tobin's Q does not measure performance: Theory, empirics, and alternative measures. Working paper, Washington University in Saint Louis and Singapore Management University.

Fairfield, P. M., and T. L. Yohn. 2001. Using asset turnover and profit margin to forecast changes in profitability. Review of Accounting Studies 6 (4): 371-85.

Fama, E. F., and J. D. MacBeth. 1973. Risk, return and equilibrium: empirical tests. Journal of Political Economy 81 (3): 607-36.

Färe, R., S. Grosskopf, B. Lindgren, and P. Roos. 1992. Productivity changes in Swedish pharmacies 1980-1989: A non-parametric Malmquist approach. Journal of Productivity Analysis 3 (1-2): 85-101.

Färe, R., S. Grosskopf, M. Norris, and Z. Shang. 1994. Productivity growth, technical progress, and efficiency change in industrialized countries. American Economic Review 84 (1): 66-83.

Frankel, R., S. P. Kothari, and J. Weber. 2006. Determinants of the informativeness of analyst research. Journal of Accounting and Economics 41 (1-2): 29-54.

Ge, W., and M. Soliman. 2007. Achieving competitive advantage through product differentiation and cost efficiency: A new approach with new insights. Working paper, University of Washington.

Greene, W. H., and D. Segal. 2004. Profitability and efficiency in the U.S. life insurance industry. Journal of Productivity Analysis 21 (3): 229-47.

Hirshleifer, D., K. Hou, and S. H. Teoh. 2009. Accruals, cash flows, and aggregate stock returns. Journal of Financial Economics 91 (3): 389-406.

Jovanovic, B. 1982. Selection and the evolution of industry. Econometrica 50 (3): 649-70.

Keh, H. T., and S. Chu. 2003. Retail productivity and scale economies at the firm level: A DEA approach. The International Journal of Management Science 31 (2): 75-82.

Kim, S., and G. Han. 2001. A decomposition of total factor productivity growth in Korean manufacturing industries: A stochastic frontier approach. Journal of Productivity Analysis 16 (3): 269-81.

Lev, B., and S. R. Thiagarajan. 1993. Fundamental information analysis. Journal of Accounting Research 31 (2): 190-215.

Leverty, J., and Y. Qian. 2010. Firm efficiency, acquisition wealth effects and target CEO retention. Working paper, University of Iowa.

Lovell, C. A. K. 1996. Applying efficiency measurement techniques to the measurement of productivity change. Journal of Productivity Analysis 7 (2-3): 329-40.

Malmquist, S. 1953. Index numbers and indifference surfaces. Trabajos de Estatistica 4: 209-42. 
Maney, K. 2003. Dell business model turns to muscle as rivals struggle. USA today. http://usatoday 30.usatoday.com/money/industries/technology/2003-01-19-dell-cover_x.htm.

Meeusen, W., and J. Van Den Broeck. 1977. Efficiency estimation from Cobb-Douglas production functions with composed error. International Economic Review 18 (2): 135-44.

Mensah, Y. M., and S.-H. Li. 1993. Measuring production efficiency in a not-for-profit setting: an extension. The Accounting Review 68 (1): 66-88.

Newey, W., and K. West. 1987. A simple, positive, semi-definite, heteroskedasticity and autocorrelation consistent covariance matrix. Econometrica 55 (3): 703-08.

Nissim, D., and S. Penman. 2001. Ratio analysis and equity valuation: From research to practice. Review of Accounting Studies 6: 109-54.

Norton, R. 1994. Which offices or stores really perform best? A new tool tells. Fortune Magazine. http://money.cnn.com/magazines/fortune/fortune_archive/1994/10/31/79913/index.htm.

Odeck, J. 2006. Identifying traffic safety best practice: An application of DEA and Malmquist indices. Omega 34 (1): 28-40.

Ohlson, J. 1995. Earnings, book values and dividends in security valuation. Contemporary Accounting Research 11 (2): 661-87.

Ou, J. A., and S. H. Penman. 1989. Financial statement analysis and the prediction of stock returns. Journal of Accounting and Economics 11 (4): 295-329.

Penman, S. H. 2007. Financial statement analysis and security valuation, 3rd ed. New York: McGraw-Hill Irwin.

Penman, S. H., and X. Zhang. 2003. Modeling sustainable earnings and P/E ratios using financial statement information. Working paper, Columbia University.

Petersen, M. A. 2009. Estimating standard errors in finance panel data sets: Comparing approaches. Review of Financial Studies 22 (1): 435-80.

Rajgopal, S., T. Shevlin, and M. Venkatachalam. 2003. Does the stock market fully appreciate the implications of leading indicators for future earnings? Evidence from order backlog. Review of Accounting Studies 8 (4): 461-92.

Richardson, S. A., R. G. Sloan, M. T. Soliman, and I. Tuna. 2005. Accrual reliability, earnings persistence and stock prices. Journal of Accounting and Economics 39 (3): 437-85.

Romer, P. 1986. Increasing returns and long-run growth. Journal of Political Economy 94 (51): 1002-037.

Rouse, P., M. Putterill, and D. Ryan. 2002. Integrated performance measurement design: Insight from an application in aircraft maintenance. Management Accounting Research 13 (2): 229-48.

Shestalova, V. 2003. Sequential Malmquist indices of productivity growth: An application to OECD industrial activities. Journal of Productivity Analysis 19 (2-3): 211-26.

Simpson, A. N. A. 2010. Analysts' use of nonfinancial information disclosures. Contemporary Accounting Research 27 (1): 249-88.

Soliman, M. T. 2008. The use of DuPont analysis by market participants. The Accounting Review 83 (3): 823-53.

Spottiswoode, C. 2000. Improving police performance: A new approach to measuring police efficiency. London: Public Services Productivity Panel, Her Majesty's Treasury.

Stone, M. 2002. How not to measure the efficiency of public services (and how one might). Journal of the Royal Statistical Society 165 (3): 405-34.

Subramanyam, K. R., and M. Venkatachalam. 2007. Earnings, cash flows, and ex post intrinsic value of equity. The Accounting Review 82 (2): 457-81.

Thanassoulis, E., R. G. Dyson, and M. J. Foster. 1987. Relative efficiency assessments using data envelopment analysis: An application to data on rates departments. Journal of the Operational Research Society 38 (5): 397-411.

Thore, S., G. Kozmetsky, and F. Phillips. 1994. DEA of financial statements data: The U.S. computer industry. Journal of Productivity Analysis 5 (3): 229-48. 
Verma, K. 1993. Managerial efficiency: A study of management buyouts. Contemporary Accounting Research 10 (1): 179-204.

Villano, R., E. Fleming, T. Farrell, and P. Fleming. 2006. Productivity change in the Australian sheep industry revised. Working paper, University of New England.

Weber, D. P. 2009. Do analysts and investors fully appreciate the implications of book-tax differences for future earnings? Contemporary Accounting Research 26 (4): 1175-206.

Weiss, D. 2010. Cost behavior and analysts' earnings forecasts. The Accounting Review 85 (4): $1441-471$.

Weiss, D., P. A. Naik, and C.-L. Tsai. 2008. Extracting forward-looking information from security prices: A new approach. The Accounting Review 83 (4): 1101-124.

Wermers, R. 2003. Is money really smart? New evidence on the relation between mutual fund flows, manager behavior, and performance persistence. Working paper, University of Maryland. 